\title{
A simple method for distinguishing global Case-1 and Case-2 waters using SeaWiFS measurements
}

\author{
Bunkei Matsushita, ${ }^{1}$ Wei Yang, ${ }^{2,1}$ Peng Chang, ${ }^{1}$ Fan Yang, ${ }^{1}$ Takehiko Fukushima ${ }^{1}$
}

${ }^{1}$ Graduate School of Life and Environmental Sciences, University of Tsukuba

1-1-1 Tennoudai, Tsukuba, Ibaraki, 305-8572, Japan

E-mail addresses: mbunkei@sakura.cc.tsukuba.ac.jp, physics722@hotmail.com, frankspare@gmail.com, fukusima@sakura.cc.tsukuba.ac.jp

${ }^{2}$ State Key Laboratory of Earth Surface Processes and Resource Ecology, Beijing Normal University, Beijing, 100875, China

E-mail address: yangwei1022@gmail.com

Submittal date: 2012-1-25

*Corresponding Author

E-mail address: yangwei1022@gmail.com 


\title{
A simple method for distinguishing global Case-1 and Case-2 waters using SeaWiFS measurements
}

\begin{abstract}
Since the combinations of water constituents are different between Case- 1 and Case- 2 waters, bio-optical models, retrieval algorithms for water constituent concentrations and other applications in water-color remote sensing are also very dissimilar between these waters. Use of the algorithms specifically developed for Case-1 waters returns inaccurate results in Case-2 waters, and vice versa. To select an appropriate algorithm for a given water pixel, it is important to first determine whether it is a Case-1 or Case-2 water and to clarify its temporal variations. This paper presents a simple method based on the inherent optical properties (IOPs) of water bodies for discriminating global Case-1 and Case-2 waters based on satellite data. Compared with the previous methods, the newly proposed method only requires two remote-sensing reflectances at $412 \mathrm{~nm}$ and $443 \mathrm{~nm}$ for relative comparisons, and thus it not only can easily be implemented using satellite data but also is robust even for satellite data with imperfect atmospheric correction, unpredictable noise pixels in the images, and so on. The new method was then applied to seasonal SeaWiFS 9-km data to map the global distribution of Case-1 and Case-2 waters for each season in 2003. The results showed that more than $80 \%$ of global waters belong to the Case- 1 category throughout the year, and the Case- 2 waters are mainly concentrated in the Northern Hemisphere along the coasts. Both the area and distribution of Case-1 and Case-2 waters changed seasonally. By using a sub-dataset from NOMAD, it was found that when the ratio of $\left[a_{\mathrm{ph}}(443)+a_{\mathrm{w}}(443)\right] / a(443)$ was larger (smaller) than $50 \%$, about 70\% (75\%) of the samples were identified as Case-1 (Case-2) waters by the new method. Moreover, the semi-analytical algorithm GSM01 was more accurate for distinguishing Case-1 than Case-2 waters, which implies that use of the proposed method to select the appropriate remote-sensing
\end{abstract}


algorithm would be important.

Key words: inherent optical properties, remote-sensing reflectance at 412 and $443 \mathrm{~nm}$, Case-1 and Case-2 waters, GSM01

\section{Introduction}

Water classification is useful to simplify the modeling of optical properties of water bodies, as well as to evaluate the performance of water color algorithms (e.g., when, where and how the algorithms may fail) (IOCCG, 2000). Generally, the global waters are classified as two types: Case-1 and Case-2 waters. The original definition of Case- 1 and Case-2 waters was from Morel and Prieur (1977). Following this initial definition, several well-defined criteria were proposed for distinguishing Case-1 and Case-2 waters (Gordon and Morel, 1983; Morel, 1988; IOCCG, 2000; Mobley et al., 2004). In the definition commonly used today, Case-1 waters are those waters whose inherent optical properties (IOPs) are dominated by phytoplankton (e.g., most open ocean waters), whereas Case-2 waters are all other waters (e.g., some coastal and inland waters contain colored dissolved organic matter (CDOM) and inorganic mineral particles in addition to phytoplankton).

Since the combinations of water constituents are different between the Case- 1 and Case-2 waters, bio-optical models, retrieval algorithms for water constituent concentrations, and other applications in water-color remote sensing are also very dissimilar between these waters (e.g., Gordon and Wang, 1994; O’Reilly et al., 1998; Morel and Maritorena, 2001; Ammenberg et al., 2002; Wang and Shi, 2007; Gitelson et al., 2009; Yang et al., 2010). Generally, use of the algorithms specifically developed for Case-1 waters returns inaccurate results in Case-2 waters (Hu et al., 2000; Dzwonkowski and Yan, 2005; Zimba and Gitelson, 2006; Wang and Shi, 2007; Van Der Woerd and Pasterkamp, 2008; Gitelson et al., 2009; Gilerson et al., 2010). On the other hand, the algorithms 
specifically developed for Case-2 waters are also difficult to apply to Case-1 waters, mainly because of the different band selection or model parameterization between the two types of waters. For instance, the three-band model, which was specifically proposed to estimate the chlorophyll- $a$ concentration in Case-2 waters, requires bands to be at red and near-infrared wavelengths to minimize the effects of non-algal particles and CDOM on phytoplankton (Gitelson et al., 2008). However, the water-leaving radiances at the near-infrared wavelengths often do not have enough signals for detection of water constituents in most Case- 1 waters, and thus will result in impossible estimates in this type of water. This is one reason why the Case-1-specific OC4 algorithm (oceanic chlorophyll- $a$ algorithm for SeaWiFS) employed remote-sensing reflectances at the blue-green bands (O’Reilly et al., 1998). Although there are some other Case-2 algorithms that used the same band combination as the Case-1 algorithms in the ocean, the reparameterization is required because the addition of other optically active substances (OASs) will invalidate the assumed relationship between the blue-green reflectance ratio and chlorophyll a concentration in Case- 1 waters (e.g., McKee et al., 2007). Therefore, to select an appropriate algorithm for a given water pixel, knowledge of whether it is a Case- 1 or Case-2 water is required, along with knowledge of its temporal variations (Lee and Hu, 2006).

Since the original definition of Case- 1 and Case- 2 waters is a qualitative one, a more quantitative definition is needed to distinguish these waters by using remote-sensing data. Some previous studies have proposed a bipartite classification scheme based on the relative contributions of phytoplankton, yellow substances and suspended material (Prieur and Sathyendranath, 1981; Morel and Antoine, 1997; Dowell, 1998; IOCCG, 2000). All these studies classified the waters based on the absorption coefficients at $440 \mathrm{~nm}$. The application of these methods to satellite data is limited due to the challenges in obtaining the absorption coefficients from remote-sensing reflectance (Lee et al., 2002). There are two other methods that can be used for selecting ocean color algorithms for 
Case-1/Case-2 waters (the fuzzy logic classification scheme in Moore et al., 2001; and the novelty detection technique in D'Alimonte et al., 2003); these methods were developed based on the structure of the training datasets and certain mathematical theories, rather than the definition of Case-1 and Case-2 waters. Moreover, a tool for identifying turbid Case-2 waters from the Coastal Zone Color Scanner (CZCS) imagery was developed by Bricaud and Morel (1987), and further improved by Morel and Belanger (2006; hereafter denoted as MB) by considering an improved field database (both in number and quality) and the bidirectional character of the light field emerging from a water body. This tool can only detect sediment-dominated waters, while the identification of yellow substance-dominated Case-2 waters was not considered (Morel and Belanger, 2006).

An alternative method for quantitatively classifying global waters as Case-1 or Case- 2 was proposed by Lee and Hu (2006; hereafter denoted as LH). They defined two criteria based on a Case-1 bio-optical model developed by Morel and Maritorena (2001). Two limits (though arbitrary) were also used by LH to account for imperfections and approximations of models and measurements. However, several existing studies have pointed out that the criteria used by LH are too restrictive to account for the complexity of actual conditions in oceanic environments (e.g., Morel et al., 2007; Shutler et al., 2007; Morel and Gentili, 2009). For example, although the north central and equatorial Pacific Ocean $\left(10^{\circ} \mathrm{S}-40^{\circ} \mathrm{N}\right)$ indubitably satisfy the biogeochemical definition of Case- 1 waters, these oligotrophic waters do not meet the Case-1 criterion of LH (i.e., Eq. 3a in Lee and Hu, 2006) because the LH upper limit does not allow for CDOM deficits at low concentrations of chlorophyll- $a$ (Morel and Gentili, 2009).

Consequently, the main objective of the present study was to propose a novel method, based on the characteristics of the IOPs of water constituents (i.e., phytoplankton, tripton, and CDOM), to distinguish global Case-1 and Case-2 waters from satellite data. Four seasonal SeaWiFS satellite datasets from 2003 and three sub-datasets of the NASA bio-Optical Algorithm Dataset (NOMAD) 
were used to evaluate the performance of the proposed method.

\section{Data collection}

\subsection{SeaWiFS 9-km datasets}

SeaWiFS 9-km data (SeaWiFS Reprocessing 5) were used to map the global distribution of Case-1 and Case-2 waters. The seasonally composited remote-sensing reflectances at 412, 443, 490, and $555 \mathrm{~nm}$ for the study period were downloaded from the Goddard Space Flight Center (http://oceandata.sci.gsfc.nasa.gov/SeaWiFS/Mapped/). To enable comparison with the previous method, the data were acquired for the same period (between 23 March 2003 and 23 March 2004) as described in Lee and Hu (2006).

\subsection{NOMAD datasets}

The NASA bio-Optical Marine Algorithm Dataset (NOMAD) was also employed to evaluate the performance of the proposed method. NOMAD is a global high quality in situ bio-optical dataset for developing ocean color algorithms and validating satellite data products. It includes over 3400 stations and is publicly available (Werdell and Bailey, 2005). The data provided include spectral water-leaving radiances, surface irradiances, diffuse downwelling attenuation coefficients, and chlorophyll- $a$ concentrations (ranging from 0.012 to $72.12 \mathrm{mg} \mathrm{m}^{-3}$ ), as well as inherent optical properties (e.g., absorption coefficients for phytoplankton, tripton, and CDOM). Metadata (the date, time, and location of data collection) and ancillary data (e.g., sea surface temperatures and water depths) were also included in each record.

In this study, three sub-datasets were generated from NOMAD for different purposes of analysis. The first sub-dataset was used for validation of the relationships between remote-sensing reflectances and absorption coefficients as well as comparison between the newly proposed method 
and the LH method. Thus it requires the remote-sensing reflectance (as the ratio of the water-leaving radiance to the downwelling surface irradiance) at the SeaWiFS bands of 412, 443, 490 and $555 \mathrm{~nm}$, as well as absorption coefficients at 412 and $443 \mathrm{~nm}$ for the three water constituents. Note that the NOMAD dataset provides the in situ remote-sensing reflectance and total absorption coefficient at a wavelength of $411 \mathrm{~nm}$, while the central wavelength of the SeaWiFS band 1 is $412 \mathrm{~nm}$. The wavelength difference between NOMAD and SeaWiFS is ignored in this study. The second sub-dataset was used for a sensitivity analysis for the proposed method and the LH method. It only requires remote-sensing reflectance at the SeaWiFS bands of 412, 443, 490, and $555 \mathrm{~nm}$. The third one was used to evaluate the accuracy of a semi-analytical algorithm (i.e., the Garver-Siegel-Maritorena model, GSM01) in estimating chlorophyll $a$ for Case-1 and Case-2 waters, respectively. It requires that chlorophyll- $a$ concentrations be measured by the HPLC (high performance liquid chromatography) method, as well as the remote-sensing reflectance at the SeaWiFS bands of 412, 443, 490, 510 and $555 \mathrm{~nm}$. The other NOMAD data with fluorometric chlorophyll measurements were not used in this analysis because of the higher noises in the fluorometric measurements (Campbell and Feng, 2005). Therefore, after the elimination of stations, those missing any of the above requirements, which were the 518, 2208, and 870 stations, remained in the subsequent analysis for the first, second and third sub-dataset, respectively (Fig. 1).

Please insert Fig. 1 here

\section{Development of a new method for distinguishing Case-1 and Case- 2 waters}

\subsection{IOPs of a natural water body}

The IOPs specify the optical properties of a water body in a form suited for use in radiative transfer theory (Mobley, 1994). They are generally determined by four OASs. The OASs are defined 
in this study as: (1) pure water molecules; (2) living phytoplankton; (3) tripton, i.e., the non-algal particulate matter, including detritus generated by living phytoplankton and other inorganic materials; and (4) colored dissolved organic matter (CDOM), or yellow substances, including those resulting from biological activities and from environmental input. This definition is akin to that of Bricaud et al. (1998), except that the latter was specifically for oceanic Case-1 waters, and therefore the tripton and CDOM were both associated with phytoplankton.

Absorption and backscattering coefficients are two fundamental IOPs for the four OASs. Fig. 2 shows an example of the two fundamental IOPs for phytoplankton, tripton, CDOM and pure water when the chlorophyll $a$ concentration is equal to $1 \mathrm{mg} \mathrm{m}^{-3}$. This example was extracted from a synthetic dataset in IOCCG Report Number 5 (2006, containing the data for 500 IOPs, available at http://www.ioccg.org/groups/OCAG data.html). The dataset was generated based on extensive field measurements (e.g., Bricaud et al., 1995; Bricaud et al., 1998; Carder et al., 1999), and random values were added to represent the variabilities from place to place.

As shown in Fig. 2A, an absorption peak by phytoplankton is found around $440 \mathrm{~nm}$ within the blue spectrum. The absorption spectrum of pure water shows a slightly increasing trend in the same wavelength range. In contrast, the absorption spectra of tripton and CDOM show noticeably decreasing trends from $400 \mathrm{~nm}$ to $500 \mathrm{~nm}$, and the absorption coefficients of both tripton and CDOM can be described as exponential functions. In addition, the backscattering spectra of phytoplankton, tripton and pure water show a monotonic decrease and very small magnitude within the blue spectrum compared with their absorption spectra (Fig. 2B).

Generally, the total absorption $(a(\lambda))$ and backscattering $\left(b_{\mathrm{b}}(\lambda)\right)$ coefficients of a water body are respectively expressed as:

$$
\begin{aligned}
& a(\lambda)=a_{\mathrm{w}}(\lambda)+a_{\mathrm{ph}}(\lambda)+a_{\mathrm{tr}}(\lambda)+a_{\mathrm{CDOM}}(\lambda) \\
& b_{\mathrm{b}}(\lambda)=b_{\mathrm{b}, \mathrm{w}}(\lambda)+b_{\mathrm{b}, \mathrm{ph}}(\lambda)+b_{\mathrm{b}, \mathrm{rr}}(\lambda)
\end{aligned}
$$


where $a_{\mathrm{w}}(\lambda), a_{\mathrm{ph}}(\lambda), a_{\mathrm{tr}}(\lambda)$ and $a_{\mathrm{CDOM}}(\lambda)$ are the absorption coefficients for pure water, phytoplankton, tripton and CDOM, respectively; and $b_{\mathrm{b}, \mathrm{w}}(\lambda), b_{\mathrm{b}, \mathrm{ph}}(\lambda)$ and $b_{\mathrm{b}, \mathrm{rr}}(\lambda)$ are backscattering coefficients for pure water, phytoplankton and tripton, respectively.

Please insert Fig. 2 here

\subsection{Relative contribution of phytoplankton}

Classification of water types in IOCCG (2000) is based on the relative contributions to an optical property from three OASs: phytoplankton, yellow substances (i.e., CDOM) and suspended material. For instance, by using the absorption coefficients at $443 \mathrm{~nm}$, the relative contribution from phytoplankton can be expressed as the ratio $a_{\mathrm{ph}}(443) /\left[a_{\mathrm{ph}}(443)+a_{\mathrm{tr}}(443)+a_{\mathrm{CDOM}}(443)\right]$. All Case- 1 waters would have high contribution values for phytoplankton. Note that pure water cannot be classified as Case-1 or Case-2 water according to the classification scheme of IOCCG (2000) because the contribution from pure water was not considered.

Consequently, the relative contribution from phytoplankton is re-defined in this study as:

$$
\begin{aligned}
& {\left[a_{\mathrm{w}}(443)+a_{\mathrm{ph}}(443)\right] /\left[a_{\mathrm{w}}(443)+a_{\mathrm{ph}}(443)+a_{\mathrm{tr}}(443)+a_{\mathrm{CDOM}}(443)\right]} \\
& =\left[a_{\mathrm{w}}(443)+a_{\mathrm{ph}}(443)\right] / a(443)
\end{aligned}
$$

where the absorption of pure water at $443 \mathrm{~nm}, a_{\mathrm{w}}(443)$, is constant. In this way, the pixels of pure or nearly pure water (i.e., in the case of contributions from phytoplankton, tripton and CDOM all can be ignored) will also have high phytoplankton contributions, and consequently will be classified as Case-1 waters.

3.3 Relationships among $\left[a_{\mathrm{ph}}(443)+a_{\mathrm{w}}(443)\right] / a(443), a(412) / a(443)$, and $R_{\mathrm{rs}}(412) / R_{\mathrm{rs}}(443)$

In this study, the two wavelengths of 412 and $443 \mathrm{~nm}$ were selected for further analysis based on Fig.2. The ratio between the absorption coefficients at these two bands can be calculated as 
follows:

$$
\begin{aligned}
& a(412) / a(443) \\
& =\frac{\left[a_{\mathrm{w}}(412)+a_{\mathrm{ph}}(412)+a_{\mathrm{tr}}(412)+a_{\mathrm{CDOM}}(412)\right]}{\left[a_{\mathrm{w}}(443)+a_{\mathrm{ph}}(443)+a_{\mathrm{tr}}(443)+a_{\mathrm{CDOM}}(443)\right]}
\end{aligned}
$$

From Fig. 2A, the following relationships can be obtained for these two bands:

$$
\begin{aligned}
& a_{\mathrm{w}}(412)<a_{\mathrm{w}}(443) \\
& a_{\mathrm{ph}}(412)<a_{\mathrm{ph}}(443) \\
& a_{\mathrm{tr}}(412)>a_{\mathrm{tr}}(443) \\
& a_{\mathrm{CDOM}}(412)>a_{\mathrm{CDOM}}(443)
\end{aligned}
$$

According to Equations (4)-(8), it can be considered that the value of $a(412) / a(443)$ will decrease when the amount of phytoplankton increases. In other words, there should be a negative correlation between the ratio $a(412) / a(443)$ and the relative contribution of phytoplankton, as defined in Eq. (3).

To confirm the above deduction, regression analysis was performed between $\left[a_{\mathrm{ph}}(443)+a_{\mathrm{w}}(443)\right] / a(443)$ and $a(412) / a(443)$ based on the first sub-dataset from NOMAD (Fig. 3A). A significant negative correlation relationship was obtained $\left(\mathrm{R}^{2}=0.43\right.$ and $\left.P<0.001\right)$, i.e.,

$$
a(412) / a(443)=-0.5784\left[a_{\mathrm{ph}}(443)+a_{\mathrm{w}}(443)\right] / a(443)+1.4771
$$

It can be seen that when $\left[a_{\mathrm{ph}}(443)+a_{\mathrm{w}}(443)\right] / a(443)$ is larger than $50 \%$, the ratio of $a(412) / a(443)$ should be approximately smaller than 1.2.

The absorption coefficient can be related with remote-sensing reflectance by taking the backscattering coefficient into consideration. From Fig. 2B and Eq. (2), the following relationship of backscattering coefficients can always be obtained:

$$
b_{\mathrm{b}}(412)>b_{\mathrm{b}}(443)
$$

According to Gordon et al. (1988), the remote-sensing reflectance is proportional to backscattering coefficients, but inversely proportional to absorption coefficients. Therefore, the ratio of the 
remote-sensing reflectance at 412 and $443 \mathrm{~nm}\left(R_{\mathrm{rs}}(412) / R_{\mathrm{rs}}(443)\right)$ should be inversely proportional to the ratio of absorption coefficients at these two bands (i.e., $a(412) / a(443)$ ). Fig. 3B shows the scatter plots of $R_{\mathrm{rs}}(412) / R_{\mathrm{rs}}(443)$ versus $a(412) / a(443)$ using the first sub-dataset from NOMAD. A significant negative correlation relationship was also obtained between these two ratios $\left(R^{2}=0.41\right.$, $P<0.001)$, i.e.,

$$
R_{\mathrm{rs}}(412) / R_{\mathrm{rs}}(443)=-0.8406 a(412) / a(443)+2.0206
$$

Please insert Fig. 3 here

\subsection{Remote-sensing criterion for distinguishing Case-1 and Case-2 waters}

In this study, for the convenience of mapping global waters, the waters with a phytoplankton contribution larger than $50 \%$ (i.e., $\left[a_{\mathrm{ph}}(443)+a_{\mathrm{w}}(443)\right] / a(443) \geq 50 \%$ ) are considered as Case- 1 waters, and those with a smaller phytoplankton contribution are considered as Case-2 waters. This cut-off value of $50 \%$ is used following the definition that "the IOPs of Case- 1 waters are dominated by phytoplankton.” Correspondingly, the Case-1 waters should satisfy the following relationship based on Eq. 9:

$$
a(412) / a(443) \leq 1.2
$$

From Eq.(11), it is clear that $a(412) / a(443) \leq 1.2$ corresponds with $R_{\mathrm{rs}}(412) / R_{\mathrm{rs}}(443) \geq 1.0$.

Accordingly, a novel remote-sensing criterion to distinguish Case-1 and Case-2 waters based on the two wavelengths of 412 and $443 \mathrm{~nm}$ (corresponding to SeaWiFS bands 1 and 2) is proposed here. It is:

If $R_{\mathrm{rs}}(412) \geq R_{\mathrm{rs}}(443)$, then the pixel is a Case- 1 water

Otherwise, it is a Case-2 water. 


\section{Results}

\subsection{Global distribution of Case-1 and Case-2 waters by the proposed method}

The ratio of $R_{\mathrm{rs}}(412) / R_{\mathrm{rS}}(443)$ was first calculated using SeaWiFS satellite data for four seasons (Fig.4). The value of $R_{\mathrm{rs}}(412) / R_{\mathrm{rs}}(443)$ represents the dominance of phytoplankton and/or pure water IOPs within a water body. The global waters were grouped by changing the band-ratio value from 0.8 (less dominant) to 1.2 (more dominant) at intervals of 0.1 to demonstrate the different levels of phytoplankton dominance. It can be clearly seen that the band-ratio values increased with the distance away from the land, indicating that the IOPs of phytoplankton and/or pure water became more dominant with the change from the coast to the open ocean. The waters with large and small ratios (i.e., $R_{\mathrm{rs}}(412) / R_{\mathrm{rs}}(443) \geq 1.1$ and $\left.R_{\mathrm{rs}}(412) / R_{\mathrm{rs}}(443) \leq 0.9\right)$ were observed in open oceans and coastal areas, accounting for $60-74 \%$ and $7-11 \%$ of the total (Table 1), respectively. The waters with medium ratios $\left(0.9<R_{\mathrm{rs}}(412) / R_{\mathrm{rs}}(443)<1.1\right)$ accounted for $19-30 \%$ (Table 1$)$.

The new proposed criterion was then applied to map the global distribution of Case-1 and Case-2 waters for the four seasons (Fig.5). The results show that the Case- 1 waters account for more than $80 \%$ of the global surface water for each season. The area of Case- 1 waters varied slightly within the seasons, with the maximum percentages appearing in the autumn and winter (both 87\%), followed by the spring (83\%) and summer (81\%). Regionally, most of the North Central Pacific, Equatorial Pacific, South Pacific, North Central Atlantic, Equatorial Atlantic, South Atlantic, Equatorial Indian, and South Indian regions were found to belong to the Case-1 category.

With respect to the Case-2 waters, most of them were distributed in the Northern Hemisphere along the coast, especially in the North Pacific and the North Atlantic. Some coastal and inland water areas, such as the Bering Sea, Gulf of Alaska, Gulf of St. Laurence, Gulf of Oman, Bohai Bay, Java Sea, Sea of Okhotsk, Black Sea, Caspian Sea, and Great Lakes, were assigned to the Case-2 category for all seasons. In contrast, some coastal water areas, such as the Mediterranean Sea, Japanese Sea, 
and Red Sea, showed seasonal variation between the Case-1 and Case-2 categories.

Please insert Fig. 4 here

Please insert Fig. 5 here

Please insert Table 1 here

\subsection{Comparison between the proposed method and LH method}

\subsubsection{Direct comparison with SeaWiFS data}

For comparison, the LH method was also applied to the same SeaWiFS 9-km data to map the global distribution of Case-1 and Case-2 waters for each season (Fig.6). Since the version of SeaWiFS data has been updated, higher percentages of Case-1 waters (about 9\% higher than those in Lee and Hu, 2006) were obtained even though the criteria used were the same as in the LH method. Nevertheless, there was no substantial difference in the distribution pattern of Case- 1 and Case-2 waters between the two versions of SeaWiFS data. From Figs. 4 and 6, it is noted that the percentage of Case- 1 waters distinguished by the LH method was often smaller (9-20\%) than that distinguished by the method proposed in this study for each season. In addition, the smallest percentage of Case-1 waters estimated by the LH method appeared in winter; in contrast, the summer season showed the smallest percentage of Case- 1 waters when the method proposed in the present study was used (Fig. 4). The middle and the largest percentages of Case- 1 waters appeared in spring and autumn, respectively, which was the same between the two methods.

Fig. 7 shows a comparison of the global water classification between the LH method and the method proposed in this study. It can be seen that more than $77 \%$ (87\%, 89\%, $85 \%$, and $77 \%$ for spring, summer, autumn, and winter, respectively) of global waters were classified into the same category by both methods. The differences in the global water classification between the two 
methods mainly result from some water pixels that were classified as Case-2 waters by the LH method but were classified as Case- 1 waters by the method proposed in this study $(12 \%, 10 \%, 14 \%$, and $21 \%$ for spring, summer, autumn, and winter, respectively). Regionally, these water pixels were distributed mainly in the mid-Pacific Ocean, Mediterranean Sea (spring and autumn), and Antarctic Ocean. For all seasons, only 1\% of global waters were classified as Case- 1 waters by the LH method but as Case-2 waters by the method proposed in this study (red color pixels in Fig. 7).

Please insert Fig. 6 here

Please insert Fig. 7 here

\subsubsection{Accuracy assessment with NOMAD data}

Fig. 8 shows the scatter plots of $\mathrm{RR}_{12}\left(R_{\mathrm{rs}}(412) / R_{\mathrm{rs}}(443)\right)$ versus $\mathrm{RR}_{53}\left(R_{\mathrm{rs}}(555) / R_{\mathrm{rs}}(490)\right)$ using the first sub-dataset from NOMAD. All the samples $(\mathrm{N}=518)$ were color coded with a ratio of $\left[a_{\mathrm{ph}}(443)+a_{\mathrm{w}}(443)\right] / a(443)$. It was found that when the ratio was larger than $50 \%$, about $70 \%$ of the samples were identified as Case- 1 waters. In contrast, when the ratio was smaller than $50 \%$, more than $75 \%$ of them were identified as Case- 2 waters. The results thus indicated that the proposed criterion could act as a proxy of the IOPs of water bodies for the discrimination of Case- 1 and Case-2 waters.

These samples were also separated into five groups by using the first condition in the LH method (the details of this method are given in Appendix A) and the new criterion proposed in this study. These groups were (1) $\mathrm{RR}_{12}>1.1 \mathrm{RR}_{12}{ }^{\text {[CS1] }}$ (group I; the superscript [CS1] denotes Case-1); (2) $\mathrm{RR}_{12}<0.9 \mathrm{RR}_{12}{ }^{[\mathrm{CS} 1]}$ and $\mathrm{RR}_{12}>1$ (group II); (3) $0.9 \mathrm{RR}_{12}{ }^{[\mathrm{CS} 1]} \leq \mathrm{R}_{12} \leq 1.1 \mathrm{RR}_{12}{ }^{[\mathrm{CS} 1]}$ and $\mathrm{RR}_{12}>1$ (group III);

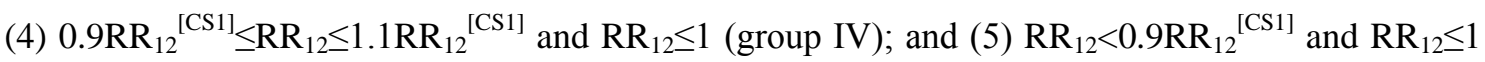
(group V), where $\mathrm{RR}_{12}{ }^{[\mathrm{CS} 1]}$ is the estimated $\mathrm{RR}_{12}$ from $\mathrm{RR}_{53}$. Group III was further divided into three 
subgroups based on the values of $\mathrm{RR}_{53}$ : (1) $\mathrm{RR}_{53}<0.4$ (group III-a); (2) $0.4 \leq \mathrm{RR}_{53} \leq 0.8$ (group III-b); and (3) $\mathrm{RR}_{53}>0.8$ (group III-c). Absorption coefficients at $440 \mathrm{~nm}$ of phytoplankton, tripton, and CDOM were also employed to indicate the relative contributions to an optical property from the three components. It should be noted that the relative contribution from phytoplankton was calculated according to the redefined one in this study (i.e., Eq.3). Descriptive statistics of the proportional contributions from each of these components are summarized in Table 2.

Please insert Fig. 8 here

Please insert Table 2 here

For group I, all the samples were classified as Case-2 waters by the LH method, but as Case-1 waters by the method proposed in this study (Fig. 8). The averaged proportional contributions of phytoplankton, CDOM, and tripton to the total absorption coefficient (except for pure water) were $60 \%, 30 \%$, and $10 \%$, respectively (Table 2). A common characteristic of the group I is that all samples had lower CDOM and thus they did not meet the Case- 1 criterion by the LH method (Lee and Hu, 2006; Morel and Gentili, 2009).

Like those of group I, all samples of group II were also classified as Case-2 waters by the LH method, but as Case-1 waters by the band-ratio criterion (Fig. 8). Nevertheless, the averaged proportional contributions of phytoplankton, CDOM, and tripton were very different from those in group I (31\% for phytoplankton, 63\% for CDOM, and 6\% for tripton; Table 2). A common characteristic of the group II is that they all had low concentrations of phytoplankton, but moderate levels of CDOM. Accordingly, these samples were distributed close to the boundaries of the LH and the band-ratio criteria (green and magenta lines in Fig. 8), and could be easily misclassified.

About half of the total number of samples was assigned to group III. All samples of group III 
were classified as Case-1 waters by the proposed method, but some of them were classified as Case-2 waters by the LH method because they did not meet the second criterion of the LH method (Equation A-3 in Appendix A). The averaged proportional contributions of phytoplankton, CDOM, and tripton were $45 \%, 47 \%$, and $8 \%$, respectively. At the subgroup level, the averaged proportional contribution of phytoplankton increased as the concentration of phytoplankton increased (i.e., as the values of $\mathrm{RR}_{53}$ increased). Especially for subgroup III-c, the averaged proportional contribution of phytoplankton became dominant (55\%).

For group IV, all samples were classified as Case-2 waters by the proposed method, but some were classified as Case-1 waters by the LH method. The averaged proportional contributions of phytoplankton, CDOM, and tripton were $41 \%, 46 \%$, and $13 \%$, respectively (Table 2). A common characteristic of the group IV samples is that they all showed both moderate phytoplankton and CDOM concentrations. Accordingly, these samples were also distributed close to the boundaries of LH and the proposed criteria (green and red lines in Fig. 8), and thus could be easily misclassified.

All samples belonging to group V were classified as Case-2 waters both by the LH method and the method proposed in this study. The averaged proportional contributions of phytoplankton, CDOM, and tripton to the total absorption coefficient were $36 \%$, 51\%, and 13\%, respectively (Table 2). A common characteristic of the group V samples is that they all had higher CDOM levels.

\subsubsection{Sensitivity analysis with NOMAD data}

To further evaluate the performance of the proposed method, a sensitivity analysis was carried out based on the second sub-dataset from NOMAD. Spectrally correlated noise was added to the remote-sensing reflectance at each band. This noise usually results from an imperfect atmospheric correction procedure, especially from errors in the aerosol correction (referred to as AC errors hereafter). Ruddick et al. (2000) provided typical values of AC errors for the wavelengths ranging 
from 412-865 nm for four combinations of atmosphere (clear or turbid) and water (clear or turbid). The sensitivity analyses were implemented by adding different percentages (ranging from $0 \%$ to $100 \%$ at intervals of 10\%) of AC errors into the measured remote-sensing reflectance. Fig. 9 shows the results of applying the proposed and LH methods to the remote-sensing reflectance data with added AC errors (only the case of clear atmosphere and water is shown as an example). The percentages for the identified Case-2 waters were calculated for each interval of AC errors using two methods. The percentages of identified Case- 2 waters by the LH method dramatically increased with the increase of AC errors. In contrast, the percentages of identified Case- 2 waters by the proposed method showed a relatively stable pattern with the increase of AC errors. It could be concluded that the proposed method is much less sensitive to the effects of AC errors compared with the LH method.

Please insert Fig. 9 here

\subsection{Comparison between the proposed method and MB method}

The MB method was proposed specifically for detecting turbid waters from ocean color sensors (Morel and Belanger, 2006). A relative difference (expressed as \%) at green wavelength (555 nm for SeaWiFS data) was defined to represent the turbidity of water bodies:

$$
\Delta R / R_{\lim }=100 \times\left(R_{\text {act }}-R_{\lim }\right) / R_{\lim }
$$

where $R_{\text {act }}$ is the actual reflectance obtained from satellite data; and $R_{\lim }$ is the upper limit of reflectance for Case-1 water as a function of chlorophyll-a concentration, which is determined through the bio-optical model MM01 (Morel and Maritorena, 2001). In this study, the upper limit of $R_{\mathrm{rs}}(555)$ for Case- 1 waters proposed by Lee and $\mathrm{Hu}(2006)$, i.e., $(1+v) R_{\mathrm{rs}}(555)^{[\mathrm{CS} 1]}$ (Eq. A-5 in Appendix A), was applied to the seasonal composited SeaWiFS data. 
Accordingly, the relative differences $\Delta R_{\mathrm{rs}}(555) / R_{\text {lim }}(555)$ were calculated from the acquired SeaWiFS images. Relative percentages of Case- 1 and Case- 2 waters distinguished by the proposed method were then calculated for each range of relative difference $\Delta R_{\mathrm{rs}}(555) / R_{\mathrm{lim}}(555)(\%)$. The results for Spring 2003 are shown in Fig. 10. It can be seen that the Case-1 waters almost occur for a relative difference $\Delta R_{\mathrm{rs}}(555) / R_{\mathrm{lim}}(555)$ between $-50 \%$ and $100 \%$, whereas the relative percentages of Case- 2 waters increase on both sides (i.e., in smaller negative and larger positive $\Delta R_{\mathrm{rs}}(555) / R_{\text {lim }}(555)$ values). When the relative difference $\Delta R_{\mathrm{rs}}(555) / R_{\lim }(555)$ is larger than $100 \%$, more than $90 \%$ of pixels are assigned to the Case- 2 category. This indicated that the turbid waters discriminated by Morel and Belanger (2006) are almost in agreement with the Case-2 waters identified by the proposed method. In the case of the negative $\Delta R_{\mathrm{rs}}(555) / R_{\lim }(555)$ values less than $-50 \%$, it can be considered that these pixels correspond with Case- $2 \mathrm{Y}$ waters (i.e., those waters are dominated by yellow substances; Morel and Belanger, 2006). Similar results were obtained for the other three seasons (data not shown).

Distribution maps of relative difference $\Delta R_{\mathrm{rs}}(555) / R_{\mathrm{lim}}(555)$ and Case-1/Case-2 waters around Europe are also shown for visual comparison (Fig. 11). It can be seen that similar $\Delta R_{\mathrm{rs}}(555) / R_{\mathrm{lim}}(555)$ values occurred in the Baltic Sea (a region typical of Case-2Y waters; Morel and Belanger, 2006), North Sea, and Northern North Atlantic (Fig. 11A), and almost all of them were discriminated as Case-2 waters (Fig. 11B), indicating that these waters are probably dominated by yellow substances (Case-2Y waters). The highly turbid zones, such as the coasts of the North Sea, Irish Sea, and English Channel, and the Mediterranean river plumes (the red color in Fig.11A), were also discriminated as Case-2 waters (Fig. 11B), indicating that these waters are dominated by sediment (Case-2S waters). 


\subsection{A sample application}

A semi-analytical ocean color algorithm, termed the Garver-Siegel-Maritorena model (GSM01; Maritorena et al., 2002) was employed to show the different performance of the GSM01 in Case-1 and Case-2 waters, respectively. The original GSM01 model is considered to be generally well suited for Case- 1 waters because its parameters were optimized from a large global Case- 1 in situ dataset (IOCCG, 2006).

The third sub-dataset from NOMAD was used to evaluate the performance of the GSM01 model $(\mathrm{N}=870)$. These data were first classified as Case-1 or Case-2 using the method proposed in this study. For each category, the GSM01 model was applied to retrieve the chlorophyll $a$ concentration. Fig. 12 shows the comparison of estimated and measured chlorophyll $a$ concentrations for the Case- 1 and Case-2 categories, respectively. It is clear that the performance of the GSM01 was significantly degraded in Case-2 waters compared with that in Case- 1 waters. The determination coefficient was reduced from 0.91 to 0.64 , and the log RMSE was increased from 0.272 to 0.392 . This is because the optical characteristics in Case- 2 waters were markedly different from those used to tune the GSM01 model. Therefore, a method that can easily and accurately identify Case- 1 or Case-2 waters is needed to provide a warning of potential misestimation of the chlorophyll $a$ concentration. The discrimination method proposed in this study can be considered to play this role.

\section{Discussion}


It has been suggested that remote-sensing algorithms for water bodies, such as chlorophyll retrieval algorithms, should be applied separately in Case-1 and Case-2 waters (IOCCG, 2000). Thus a priori information about the water types would be highly helpful for selecting the appropriate algorithms. However, water in a given locality may drift spatially and/or temporally between Case-1 and Case-2 conditions depending on the environmental forces. Therefore, an additional algorithm for simultaneously distinguishing between Case- 1 and Case- 2 waters from satellite data is needed for a given water pixel.

In this study, a simple remote sensing-based method was proposed to distinguish global Case-1 and Case-2 waters. The basic idea of the proposed method is to relate the relative contribution from phytoplankton (defined as $\left[a_{\mathrm{ph}}(443)+a_{\mathrm{w}}(443)\right] / a(443)$ ) with the ratio of remote-sensing reflectance at 412 and $443 \mathrm{~nm}$ (i.e., $R_{\mathrm{rs}}(412) / R_{\mathrm{rs}}(443)$ ), which was previously used to represent the relative abundance of CDOM per chlorophyll over non-coastal waters (Carder et al., 1999; Morel and Gentili, 2009). A binary classification of global Case- 1 and Case- 2 waters was performed by assuming that the Case- 1 waters are generally with $\left[a_{\mathrm{ph}}(443)+a_{\mathrm{w}}(443)\right] / a(443)$ larger than $50 \%$. This is somewhat consistent with the concept that the Case- 1 waters are those waters whose IOPs are dominated by phytoplankton.

Both sediment-dominated and yellow substance-dominated waters were classified as Case-2 waters in this study. The former are denoted as Case-2S waters, and can be detected by the MB method (Morel and Belanger, 2006). The results in Fig. 10 showed that most of the Case-2S waters were also distinguished as Case-2 waters in this study. The latter were denoted as Case-2Y waters, which are not considered in the MB method, but could also be detected in this study. Both water types can cause the algorithm developed for Case-1 waters to fail in such zones (Fig. 12). It can be considered that the waters can be further distinguished as Case-2S and Case-2Y by combining the proposed and MB methods. 
It should be noted that the classification results from the proposed method will be affected by any of the following:

(1) Variabilities of absorption and backscattering properties of the components. Bricaud et al. (1998) stated that for chlorophyll $a$ concentrations between 0.02 and $25 \mathrm{mg} \mathrm{m}^{-3}$, the phytoplankton-specific absorption coefficient could vary by more than 1 order of magnitude. Lee et al. (2010) pointed out that the power parameter within the model of backscattering coefficient ranged from 0 (for turbid waters) to 2.0 (for open ocean waters). The correlation between $\left[a_{\mathrm{ph}}(443)+a_{\mathrm{w}}(443)\right] / a(443)$ and $a(412) / a(443)$ will be affected by the variability of absorption; in contrast, the correlation between $a(412) / a(443)$ and $R_{\mathrm{rs}}(412) / R_{\mathrm{rs}}(443)$ will mainly be affected by the variability of backscattering. Despite the presence of these variabilities, the two significant regression results were obtained from the NOMAD dataset, although with relatively low values of $\mathrm{R}^{2}$ (Fig. 3). The NOMAD stations used were located in both open ocean and coastal areas (Fig. 1A), and thus represented the possible variabilities of the optical properties of waters. More robust relationships could be established by adding additional in situ measurements. It should also be noted that these relationships were used to determine the threshold for classification, rather than yielding predictions.

(2) Variabilities of the CDOM-chlorophyll relationships. A factor $\Phi$ was introduced by Morel and Gentili (2009) to express the change in the ratio of CDOM-chlorophyll. " $\Phi=1$ " denotes the mean relationship for global oceans; “ $\Phi>1$ ” and “ $\Phi<1$ ” represent the excess and deficit of CDOM, respectively. The LH method was developed based on the mean relationship. The requirements of rigorous Case- 1 relationships (though they relaxed them by allowing some deviation) made it difficult to address the deficit cases (e.g., the waters in the mid-Pacific were classified as Case-2 waters by the LH method due to the lower CDOM, although these waters indubitably satisfy the biogeochemical definition of Case-1 waters; Morel and Gentili, 2009). In 
contrast, the proposed method in this study stably classified these areas as Case- 1 waters for different seasons (Fig. 4). However, the proposed method will classify some productive waters with high phytoplankton-associated CDOM (i.e., excess cases) as Case-2 waters, even though the CDOM in these waters co-varied with phytoplankton concentrations and thus should belong to Case-1 waters from a biogeochemical viewpoint (Siegel et al., 2002; More and Gentili, 2009). For example, the abundance of Case-2 waters detected in the North Atlantic-North Pacific was probably the result of the Case-1 and Case-2 definitions used in this study (Figs. 4, 5, and 11). Nevertheless, from the viewpoint of selecting an appropriate algorithm, it is probably reasonable to consider these waters as Case-2 waters, because the SeaWiFS chlorophyll product showed low accuracy in these areas (Gregg and Casey, 2004). In addition, even in some Case-1 waters determined from a biogeochemical viewpoint, since the CDOM concentration is influenced by past phytoplankton concentrations and photobleaching, the CDOM concentration does not co-vary with the instantaneous chlorophyll concentration (Bricaud et al., 1981; Mobley et al., 2004). Therefore, this kind of water could also be classified as a Case-2 water.

(3) Atmospheric correction (AC) errors. Non-negligible water-leaving radiance in near-infrared bands and absorbing aerosols are the main sources of error for the atmospheric correction, especially over the coastal areas (Shi and Wang, 2007). It is difficult to derive high-quality atmospheric corrections for blue bands, since the inaccuracy increases with the decreasing wavelength (Ruddick et al., 2000). Both the proposed and LH methods apply the bands at 412 and $443 \mathrm{~nm}$, and thus the performances are affected by AC errors, as shown in the sensitivity analysis. However, since the proposed method is only based on the relative relationship between $R_{\mathrm{rs}}(412)$ and $R_{\mathrm{rs}}(443)$, its sensitivity to AC errors is noticeably lower than that of the LH method (see Fig. 9). Even so, it still needs to be stressed that an accurate atmospheric correction procedure is required for global waters, especially for coastal areas. 


\section{Conclusion}

This paper presented a simple method based on the inherent optical properties of water bodies for discriminating global Case-1 and Case-2 waters from satellite data. The new proposed method only requires two remote-sensing reflectances at $412 \mathrm{~nm}$ and $443 \mathrm{~nm}$ for relative comparisons, and thus not only makes it easy to implement satellite data but also allows relaxation of the quality of satellite data (e.g., allows for imperfect atmospheric correction, unpredictable noise pixels in the images, and so on). The results of the global distribution of Case- 1 and Case-2 waters in 2003 show that more than $80 \%$ of global waters belong to the Case- 1 category throughout the year, and the Case-2 waters are mainly concentrated in the Northern Hemisphere along the coasts. Both the area and distribution of Case-1 and Case-2 waters changed seasonally. In addition, validation results for the water color algorithm, GSM01, yielded higher accuracy for the distinguished Case-1 waters than the Case-2 waters for estimating chlorophyll $a$ concentrations.

\section{Acknowledgements}

This research was supported in part by National Natural Science Foundation of China (Grant No. 40871162), by the Grants-in-Aid for Scientific Research of MEXT from Japan (No. 20510003, No. 23404015), and also by the Global Environment Research Fund (B-0909) and the Environment Research and Technology Development Fund (S-9-4-(1)) of the Ministry of the Environment, Japan. The corresponding author is the Research Fellowship for Young Scientists founded by Japan Society for the Promotion of Science (2011-2013). The authors would like to thank three anonymous reviewers for their constructive suggentions. 


\section{Appendix A. The method for classifying global Case-1 and Case-2 waters proposed by Lee and Hu (2006; denoted as LH method in this study)}

The LH method is based on the concept that the inherent optical properties (IOPs) of Case-1 waters can be solely determined by chlorophyll- $a$ concentration (Chl- $a$; Gordon and Morel, 1983; Loisel and Morel, 1998). Therefore, for optically deep Case-1 waters, there should be a unique relationship between Chl- $a$ and remote-sensing reflectance $\left(R_{\mathrm{rs}}(\lambda)\right)$. Using the MM-01 reflectance model, Lee and $\mathrm{Hu}(2006)$ calculated $R_{\mathrm{rs}}(\lambda)$ with Chl- $a$ ranging between 0.02 and $30.0 \mathrm{mg} \mathrm{m}^{-3}$.

The following two spectral ratios were applied in the method:

$$
\mathrm{RR}_{12}=\frac{R_{\mathrm{rs}}(412)}{R_{\mathrm{rs}}(443)} \text { and } \mathrm{RR}_{53}=\frac{R_{\mathrm{rs}}(555)}{R_{\mathrm{rs}}(490)}
$$

where, $\mathrm{RR}_{53}$ is a measure of Chl- $a$ and $\mathrm{RR}_{12}$ denotes the relative abundance of CDOM per Chl- $a$. In addition, $R_{\mathrm{rs}}(555)$ represents the backscattering of particles.

Since the IOPs of Case- 1 waters can be solely determined by Chl- $a$, both $\mathrm{RR}_{12}$ and $R_{\mathrm{rs}}(555)$ can be expressed as functions of $\mathrm{RR}_{53}$. Consequently, two monotonic lines were derived by using the calculated $R_{\mathrm{rs}}(\lambda)$ :

$$
\begin{aligned}
& \mathrm{RR}_{12}^{[\mathrm{CS} 1]}=0.9351+0.113 / \mathrm{RR}_{53}-0.0217 /\left(\mathrm{RR}_{53}\right)^{2}+0.003 /\left(\mathrm{RR}_{53}\right)^{3} \\
& \mathrm{R}_{r s}(555)^{[C S 1]}=0.0006+0.0027 \mathrm{RR}_{53}-0.0004\left(\mathrm{RR}_{53}\right)^{2}-0.0002\left(\mathrm{RR}_{53}\right)^{3}
\end{aligned}
$$

where $\mathrm{RR}_{12}{ }^{[\mathrm{CS} 1]}$ and $\mathrm{R}_{\mathrm{rs}}(555)^{[\mathrm{CS} 1]}$ are the estimated $\mathrm{RR}^{12}$ and $\mathrm{R}_{\mathrm{rs}}(555)$, respectively, by $\mathrm{RR}_{53}$; the superscript [CS1] denotes Case-1.

A quantitative boundary was also defined to relax the above Case- 1 relationships because the natural waters might be much more complex than the simulation cases. A water pixel is classified as Case- 1 waters if the following two conditions can be satisfied simultaneously, and the others are Case-2. The fist condition is:

$$
(1-\gamma) \mathrm{RR}_{12}^{[C S 1]} \leq \mathrm{RR}_{12} \leq(1+\gamma) \mathrm{RR}_{12}^{[C S 1]}
$$


and the second one is:

$$
(1-v) R_{\mathrm{rs}}^{[C S 1]}(555) \leq R_{\mathrm{rs}}(555) \leq(1+v) R_{\mathrm{rs}}^{[C S 1]}(555)
$$

where $\gamma=0.1$ and $v=0.5$, implying a $\pm 10 \%$ deviation of $\mathrm{RR}_{12}$ and a $\pm 50 \%$ deviation of $R_{\mathrm{rs}}(555)$ around their exact Case-1 values.

\section{References}

Ammenberg, P., Flink, P., Lindell, T., Pierson, D., Strombeck, N., 2002. Bio-optical modelling combined with remote sensing to assess water quality. International Journal of Remote Sensing 23 (8), 1621-1638.

Bricaud, A., Babin, M., Morel, A., Claustre, H, 1995. Variability in the chlorophyll-specific absorption coefficients of natural phytoplankton: Analysis and parameterization. Journal of Geophysycal Research- Oceans 100 (C7), 13321-13332.

Bricaud, A., Morel, A., 1987. Atmospheric corrections and interpretation of marine radiances in CACS imagery: Use of a reflectance model. Oceanologica Acta, 33-50.

Bricaud, A., Morel, A., Babin, M., Allali, K., Claustre, H., 1998. Variations of light absorption by suspended particles with chlorophyll a concentration in oceanic (case 1) waters: Analysis and implications for bio-optical models. Journal of Geophysical Research- Oceans 103 (C13), 31033-31044.

Bricaud, A., Morel , A., Prieur, L., 1981. Absorption by dissolved organic matter of sea (Yellow substance) in the UV and visible domains. Liminology and Oceanography 26 (1), 43-53.

Campbell, J.W., Feng, H., 2005. Quantifying the performance of a chlorophyll algorithm: Demonstration using the OC4.v4 algorithm and NOMAD data. In, Ocean Color Bio-optical Algorithm Mini Workshop (OCBAM). Durham: University of New Hampshire.

Carder, K.L., Chen, F.R., Lee, Z.P., Hawes, S.K., Kamykowski, D., 1999. Semianalytic 
Moderate-Resolution Imaging Spectrometer algorithms for chlorophyll a and absorption with bio-optical domains based on nitrate-depletion temperatures. Journal of Geophysical ResearchOceans 104 (C3), 5403-5421.

D'Alimonte, D., Mélin, F., Zibordi, G., Berthon, J., 2003. Use of the Novelty Detection Technique to Identify the Range of Applicability of Empirical Ocean Color Algorithms. IEEE Transactions on Geoscience and Remote Sensing 41 (12), 2833-2843.

Dowell, M.D., 1998. Optical characterisation and reflectance modelling in Case II waters: quantitatives tools for investigations of coastal environments. Southampton, UK: University of Southampton, pp. 192.

Dzwonkowski, B., Yan, X.H., 2005. Development and application of a neural network based ocean colour algorithm in coastal waters. International Journal of Remote Sensing 26 (6), 1175-1200.

Gilerson, A.A., Gitelson, A.A., Zhou, J., Gurlin, D., Moses, W., Ioannou, I., Ahmed, S.A., 2010. Algorithms for remote estimation of chlorophyll-a in coastal and inland waters using red and near infrared bands. Optics Express 18 (23), 24109-24125.

Gitelson, A.A., Dall'Olmo, G., Moses, W., Rundquist, D.C., Barrow, T., Fisher, T.R., Gurlin, D., Holz, J., 2008. A simple semi-analytical model for remote estimation of chlorophyll-a in turbid waters: Validation. Remote Sensing of Environment 112 (9), 3582-3593.

Gitelson, A.A., Gurlin, D., Moses, W.J., Barrow, T., 2009. A bio-optical algorithm for the remote estimation of the chlorophyll-a concentration in case 2 waters. Environmental Research Letters 4 (4), doi:10.1088/1748-9326/4/4/045003.

Gordon, H.R., Brown, O.B., Evans, R.H., Brown, J.W., Smith, R.C., Baker, K.S., Clark, D.K., 1988. A semianalytic radiance model of ocean color. Journal of Geophysical Research, 93 (D9), 10909-10924

Gordon, H.R., Morel, A.Y., 1983. Remote assessment of ocean color for interpretation of satellite 
visible imagery: a review. Springer-Verlag, New York.

Gordon, H.R., Wang, M., 1994. Retrieval of water-leaving radiance and aerosol optical thickness over the oceans with SeaWiFS: a preliminary algorithm. Applied Optics 33 (3), 443-452.

Gregg, W.W., Casey, N.W., 2004. Global and regional evaluation of the SeaWiFS chlorophyll data set. Remote Sensing of Environment 93 (4), 463-479.

Hu, C.M., Carder, K.L., Muller-Karger, F.E., 2000. Atmospheric correction of SeaWiFS imagery over turbid coastal waters: A practical method. Remote Sensing of Environment 74 (2), 195-206.

IOCCG, 2000. Remote Sensing of Ocean Colour in Coastal, and Other Optically-Complex Waters. In: S. Sathyendranath (Ed.), Reports of the International Ocean-Colour Coordinating Group. , IOCCG, Dartmouth, Canada, pp. 1-139.

IOCCG, 2006. Remote Sensing of Inherent Optical Properties: Fundamentals ,Tests of Algorithms, and Applications. In: Z. Lee (Ed.), Reports of the International Ocean-Colour Coordinating Group IOCCG, Dartmouth, Canada, pp. 1-126.

Lee, Z., Carder, K. L., Arnone, R. A., 2002. Deriving inherent optical properties from water color: a multiband quai-analytical algorithm for optically deep waters. Applied Optics 41 (27), 5755-5772.

Lee, Z., Hu, C., 2006. Global distribution of Case-1 waters: An analysis from SeaWiFS measurements. Remote Sensing of Environment 101 (2), 270-276.

Lee, Z.P., Arnone, R., Hu, C., Werdell, J., Lubac, B., 2010. Uncertainties of optical parameters and their propagations in an analytical ocean color inversion algorithm. Applied Optics 49 (3), 369-381.

Maritorena, S., Siegel, D.A., Peterson, A.R., 2002. Optimization of a semianalytical ocean color model for global-scale applications. Applied Optics 41 (15), 2705-2714.

McKee, D., Cunningham, A., Dudek, A., 2007. Optical water type discrimination and tuning remote 
sensing band-ratio algorithms: Application to retrieval of chlorophyll and K-d(490) in the Irish and Celtic Seas. Estuarine Coastal and Shelf Science, 73 (3-4), 827-834.

Mobley, C.D., 1994. Light and Water: Radiative Transfer in Natural Waters. Academic Press, San Diego.

Mobley, C.D., Stramski, D., Bissett, W.P., Boss, E., 2004. Optical modeling of ocean waters: Is the Case 1 -Case 2 classification still useful? Oceanography 17 (2), 60-67.

Moore, T.S., Campbell, J.W., Feng, H., 2001. A fuzzy logic classification scheme for selecting and blending satellite ocean color algorithms. IEEE Transactions on Geoscience and Remote Sensing 39 (8), 1764-1776.

Morel, A., 1988. Optical modeling of the upper ocean in relation to its biogenous matter content (case I waters). Journal of Geophysical Research- Oceans 93 (C9), 10749-10768.

Morel , A., Antoine, D., 1997. Pigment index retrieval in Case 1 waters. ATBD 2.9 - MERIS Workshop. In. Villefranche-sur-mer.

Morel , A., Belanger, S., 2006. Improved detection of turbid waters from ocean color sensors information. Remote Sensing of Environment 102 (3-4), 237-249.

Morel, A., Claustre, H., Antoine, D., Gentili, B, 2007. Natural variability of bio-optical properties in Case 1 waters: attenuation and reflectance within the visible and near-UV spectral domains, as observed in South Pacific and Mediterranean waters. Biogeosciences 4 (5), 913-925.

Morel , A., Gentili, B., 2009. A simple band ratio technique to quantify the colored dissolved and detrital organic material from ocean color remotely sensed data. Remote Sensing of Environment 113 (5), 998-1011.

Morel, A., Maritorena, S., 2001. Bio-optical properties of oceanic waters: A reappraisal. Journal of Geophysical Research- Oceans 106 (C4), 7163-7180.

Morel , A., Prieur, L., 1977. Analysis of variations in ocean color. Limnology and Oceanography 22 
(4), 709-722.

O'Reilly, J.E., Maritorena, S., Mitchell, B.G., Siegel, D.A., Carder, K.L., Garver, S.A., Kahru, M., McClain, C., 1998. Ocean color chlorophyll algorithms for SeaWiFS. Journal of Geophysical Research-Oceans 103 (C11), 24937-24953.

Prieur, L., Sathyendranath, S., 1981. An optical classification of coastal and oceanic waters based on the specific spectral absorption curves of phytoplankton pigments, dissolved organic matter, and other particukate materials. Limnology and Oceanography 29 (4), 671-689.

Ruddick, K.G., Ovidio, F., Rijkeboer, M., 2000. Atmospheric Correction of SeaWiFS Imagery for Turbid Coastal and Inland Waters. Applied Optics 39 (6), 897-912.

Shi, W., Wang, M., 2007. Detection of turbid waters and absorbing aerosols for the MODIS ocean color data processing. Remote Sensing of Environment 110 (2), 149-161.

Shutler, J.D., Land, P.E., Smyth, T.J., Groom, S.B., 2007. Extending the MODIS 1 km ocean colour atmospheric correction to the MODIS $500 \mathrm{~m}$ bands and $500 \mathrm{~m}$ chlorophyll-a estimation towards coastal and estuarine monitoring. Remote Sensing of Environment, 107 (4), 521-532.

Siegel, D.A., Maritorena, S., Nelson, N.B., Hansell, D.A., Lorenzi-Kayser, M., 2002. Global distribution and dynamics of colored dissolved and detrital organic materials. Journal of Geophysical Research- Oceans 107 (C12), doi:10.1029/2001JC000965.

Van Der Woerd, H.J., Pasterkamp, R., 2008. HYDROPT: A fast and flexible method to retrieve chlorophyll-a from multispectral satellite observations of optically complex coastal waters. Remote Sensing of Environment 112 (4), 1795-1807.

Wang, M., Shi, W., 2007. The NIR-SWIR combined atmospheric correction approach for MODIS ocean color data processing. Optic Express 15 (24), 15722-15733.

Werdell, P.J., Bailey, S.W., 2005. An improved in-situ bio-optical data set for ocean color algorithm development and satellite data product validation. Remote Sensing of Environment 98 (1), 
$122-140$.

Yang, W., Matsushita, B., Chen, J., Fukushima, T., Ma, R., 2010. An Enhanced Three-Band Index for Estimating Chlorophyll-a in Turbid Case-II Waters:Case Studies of Lake Kasumigaura, Japan, and Lake Dianchi, China. IEEE Geoscience and Remote Sensing Letters 7 (4), 655-659.

Zimba, P.V., Gitelson, A.A., 2006. Remote estimation of chlorophyll concentration in hypereutrophic aquatic systems:Model tuning and accuracy optimization. Aquaculture 256 (1-4), 272-286. 


\section{List of Tables}

Table 1 Percentages of water pixels within different ranges of the $R_{\mathrm{rs}}(412) / R_{\mathrm{rs}}(443)$ ratios for four seasons.

\begin{tabular}{lcccccc}
\hline $\mathrm{R}_{\mathrm{rs}}(412) / \mathrm{R}_{\mathrm{rs}}(443)$ & $0-0.8$ & $0.8-0.9$ & $0.9-1.0$ & $1.0-1.1$ & $1.1-1.2$ & $1.2-$ \\
\hline Spring & $6.6 \%$ & $4.1 \%$ & $6.5 \%$ & $17.2 \%$ & $24.3 \%$ & $41.5 \%$ \\
Summer & $5.5 \%$ & $4.6 \%$ & $9.0 \%$ & $20.8 \%$ & $24.7 \%$ & $35.3 \%$ \\
Autumn & $3.7 \%$ & $3.2 \%$ & $5.9 \%$ & $13.6 \%$ & $30.7 \%$ & $42.9 \%$ \\
Winter & $4.1 \%$ & $3.0 \%$ & $6.3 \%$ & $14.1 \%$ & $31.8 \%$ & $40.7 \%$ \\
\hline
\end{tabular}

Table 2 Descriptive statistics of the fractional contributions (calculated by the absorption coefficients at $443 \mathrm{~nm}$ ) due to phytoplankton ( $\left.P \_a p h\right)$, tripton ( $\left.P \_a t r\right)$ and CDOM $\left(P \_a C D O M\right)$ for the five groups $(\mathrm{I} \sim \mathrm{V})$ of the extracted NOMAD dataset.

\begin{tabular}{|c|c|c|c|c|c|c|c|c|}
\hline \multicolumn{2}{|c|}{ Group } & I & II & III (a) & III (b) & III (c) & IV & V \\
\hline \multicolumn{2}{|c|}{ Number of samples } & 31 & 30 & 141 & 110 & 29 & 25 & 152 \\
\hline \multirow[t]{4}{*}{ P_aph } & Max & $88.0 \%$ & $59.3 \%$ & $71.8 \%$ & $70.5 \%$ & $78.7 \%$ & $73.1 \%$ & $60.5 \%$ \\
\hline & Min & $13.6 \%$ & $5.7 \%$ & $6.2 \%$ & $6.4 \%$ & $25.4 \%$ & $14.6 \%$ & $7.7 \%$ \\
\hline & Median & $64.4 \%$ & $27.8 \%$ & $43.9 \%$ & $46.1 \%$ & $56.7 \%$ & $43.0 \%$ & $36.0 \%$ \\
\hline & Average & $59.9 \%$ & $31.1 \%$ & $42.9 \%$ & $44.2 \%$ & $55.2 \%$ & $40.8 \%$ & $36.2 \%$ \\
\hline \multirow[t]{4}{*}{ P_atr } & Max & $33.5 \%$ & $11.4 \%$ & $30.1 \%$ & $26.9 \%$ & $18.3 \%$ & $32.2 \%$ & $60.2 \%$ \\
\hline & Min & $2.8 \%$ & $0.7 \%$ & $1.8 \%$ & $2.3 \%$ & $3.6 \%$ & $2.5 \%$ & $1.8 \%$ \\
\hline & Median & $7.9 \%$ & $6.0 \%$ & $6.7 \%$ & $8.0 \%$ & $8.1 \%$ & $13.8 \%$ & $10.7 \%$ \\
\hline & Average & $9.7 \%$ & $5.8 \%$ & $7.3 \%$ & $8.9 \%$ & $9.0 \%$ & $13.2 \%$ & $13.3 \%$ \\
\hline \multirow[t]{4}{*}{ P_aCDOM } & Max & $81.7 \%$ & $93.6 \%$ & $90.0 \%$ & $80.4 \%$ & $58.6 \%$ & $82.7 \%$ & $89.5 \%$ \\
\hline & Min & $1.6 \%$ & $34.3 \%$ & $17.2 \%$ & $18.9 \%$ & $10.6 \%$ & $19.2 \%$ & $13.9 \%$ \\
\hline & Median & $27.2 \%$ & $66.1 \%$ & $48.3 \%$ & $45.4 \%$ & $35.9 \%$ & $43.1 \%$ & $50.1 \%$ \\
\hline & Average & $30.4 \%$ & $63.1 \%$ & $49.8 \%$ & $46.9 \%$ & $35.8 \%$ & $46.0 \%$ & $50.5 \%$ \\
\hline
\end{tabular}




\section{List of Figures}

Figure 1. Data locations of the three sub-datasets generated from the NASA bio-Optical Marine Algorithm Dataset (NOMAD). Filled circles and open stars represent the locations classified as Case- 1 and Case-2 waters, respectively, using the method proposed in this study.

Figure 2. Examples of (A) absorption coefficients for phytoplankton, tripton, CDOM and pure water; and (B) backscattering coefficients for phytoplankton, tripton and pure water; the chlorophyll $a$ concentration ([C]) was equal to $1 \mathrm{mg} \mathrm{m}^{-3}$. The data were selected from an IOP dataset used in IOCCG (2006), which contained 500 IOP data points. The two arrowheads denote the two bands (around 410 and $440 \mathrm{~nm}$ ) used in the proposed method of this study.

Figure 3. Scatter plots of (A) the proportion of phytoplankton absorption $\left(a_{\mathrm{ph}}(443)\right)$ and pure water absorption $\left(a_{\mathrm{w}}(443)\right)$ within the total absorption at $443 \mathrm{~nm}(a(443))$ vs. the ratio of absorption coefficients at wavelengths 412 and $443 \mathrm{~nm}(a(412) / a(443))$; (B) the ratio of $a(412)$ and $a(443)$ vs. band ratio of remote-sensing reflectance at 412 and $443 \mathrm{~nm}\left(R_{\mathrm{rs}}(412) / R_{\mathrm{rs}}(443)\right.$.

Figure 4. Global distribution of waters within different ranges of the $R_{\mathrm{rs}}(412) / R_{\mathrm{rs}}(443)$ ratios for spring, summer and autumn 2003, and winter 2004. The larger ratios imply that the IOP of phytoplankton and/or pure water are more dominant in the water bodies.

Figure 5. Global distribution of Case-1 (blue color) and Case-2 (green color) waters for spring, summer and autumn 2003, and winter 2004, distinguished by the method proposed in this study.

Figure 6. Global distribution of Case-1 (blue color) and Case-2 (green color) waters for spring, summer and autumn 2003, and winter 2004, distinguished by the LH method.

Figure 7. Comparison of global water classification between the LH method and the proposed method for spring, summer and autumn 2003, and winter 2004. Cyan denotes that the pixels were classified as the same category by both methods; green denotes that the pixels were classified as Case- 2 waters by the LH method but classified as Case- 1 waters by the method proposed in this study; and red denotes that the pixels were classified as Case- 1 waters by the LH method but classified as Case-2 waters by the method proposed in this study.

Figure 8. Scatter plots of $\mathrm{RR}_{12}\left(R_{\mathrm{rs}}(412) / R_{\mathrm{rs}}(443)\right)$ versus $\mathrm{RR}_{53}\left(R_{\mathrm{rs}}(555) / R_{\mathrm{rs}}(490)\right)$ for the selected 
MOMAD dataset (the first sub-data set, $\mathrm{N}=518$ ). The samples were separated as five groups (see text for details). Groups I, II, III, IV and V are denoted with diamonds, triangles, circles, squares and crosses, respectively. The points in green, blue, cyan, and red colors represent the samples with the proportion of phytoplankton absorption (443 nm) between 10-30\%, 30-50\%, 50-70\%, and 70-90\%, respectively.

Figure 9. (A) Reflectance error associated with atmospheric correction at different wavelengths. (B) The percentage of distinguished Case-2 waters against the noise level in $R_{\mathrm{rs}}$ for the proposed (squares) and LH (circles) methods (the second sub-data set was used, $\mathrm{N}=2208$ ).

Figure 10. Relative percentage of Case-1 and Case-2 waters within different levels of turbidity for the spring in 2003. The numbers in parenthesis (top of bars) represent the percentages of each turbidity level within the global waters.

Figure 11. (A) Relative differences for the wavelength of $555 \mathrm{~nm}$ around Europe by applying Eq. (12) to seasonally composited SeaWiFS (Spring 2003). (B) Distribution map of Case-1 (blue) and Case-2 (green) waters for the same area.

Figure 12. Comparison of the GSM01 performance between Case-1 and Case-2 waters. The third sub-dataset was used, and the invalid retrievals were eliminated (52 stations in total). 


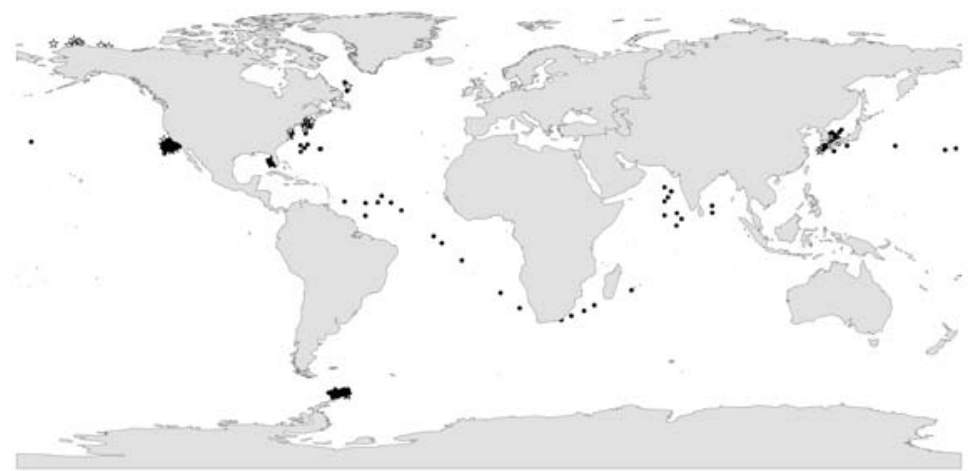

(A) The first sub-dataset $(\mathrm{N}=518)$

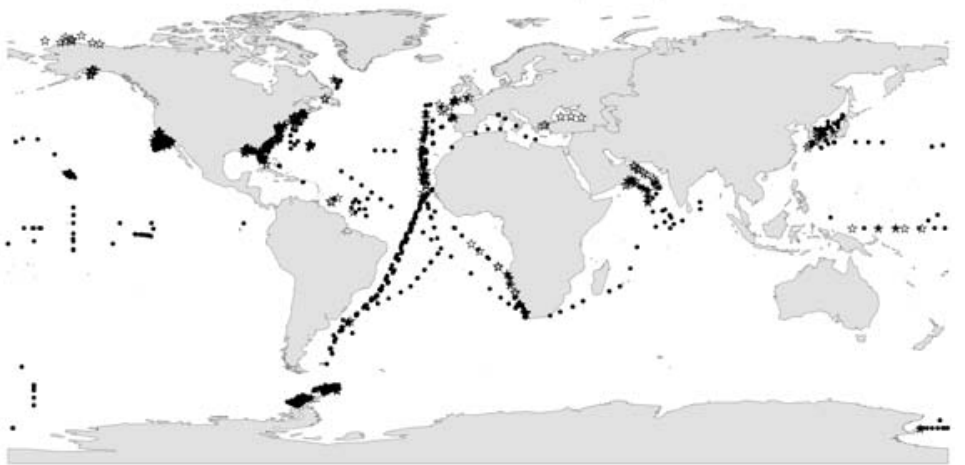

(B) The second sub-dataset ( $\mathrm{N}=2208$ )

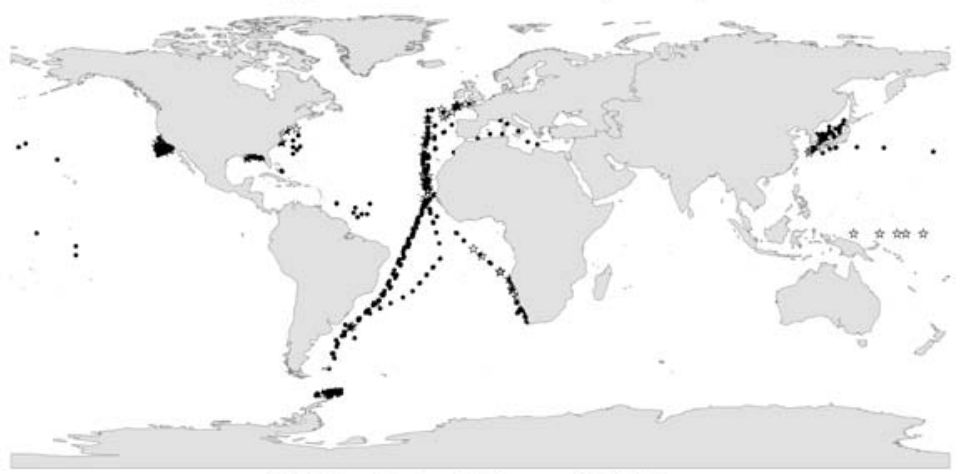

(C) The third sub-dataset $(\mathrm{N}=870)$

Fig. 1 

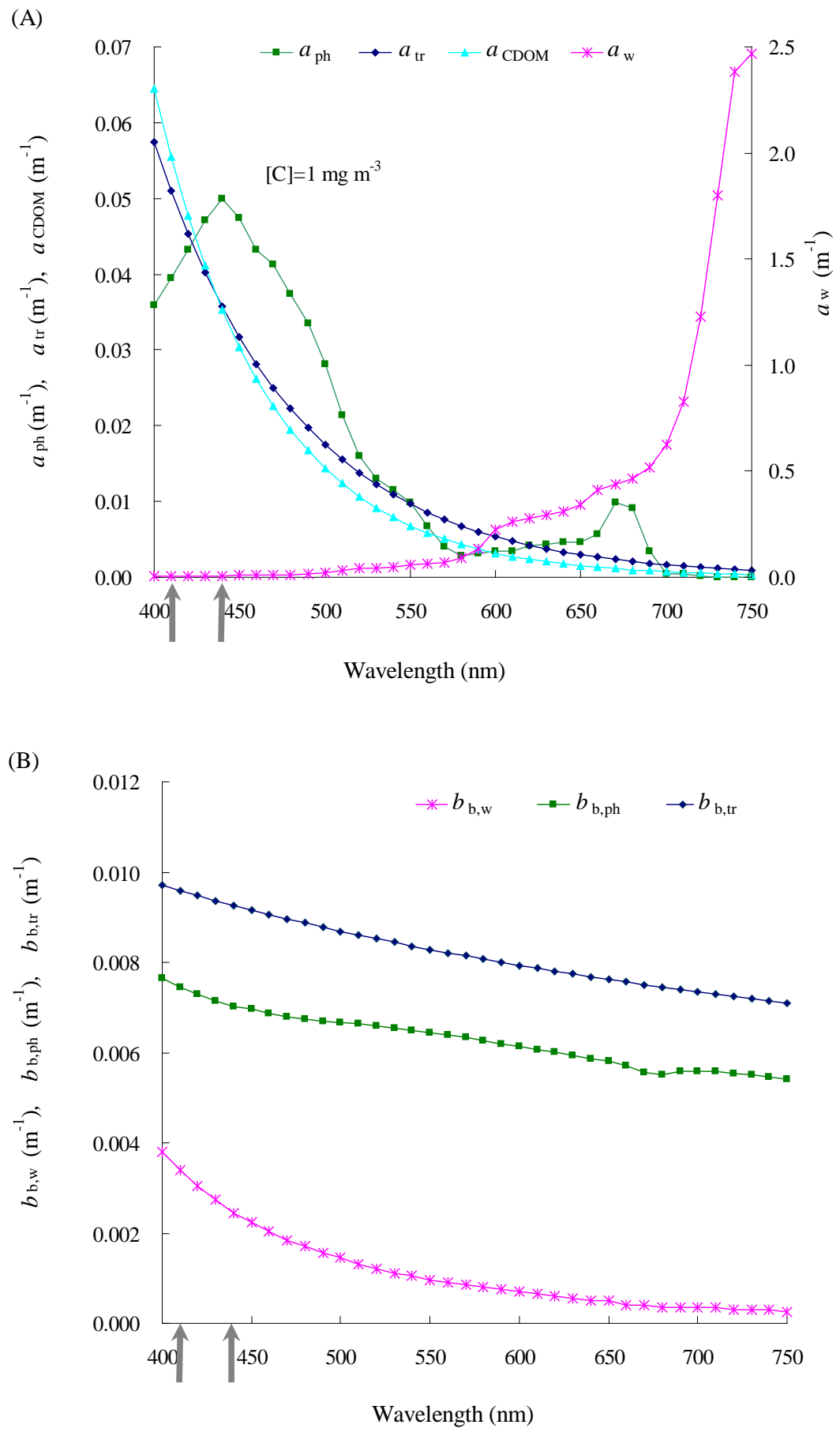

Fig. 2 

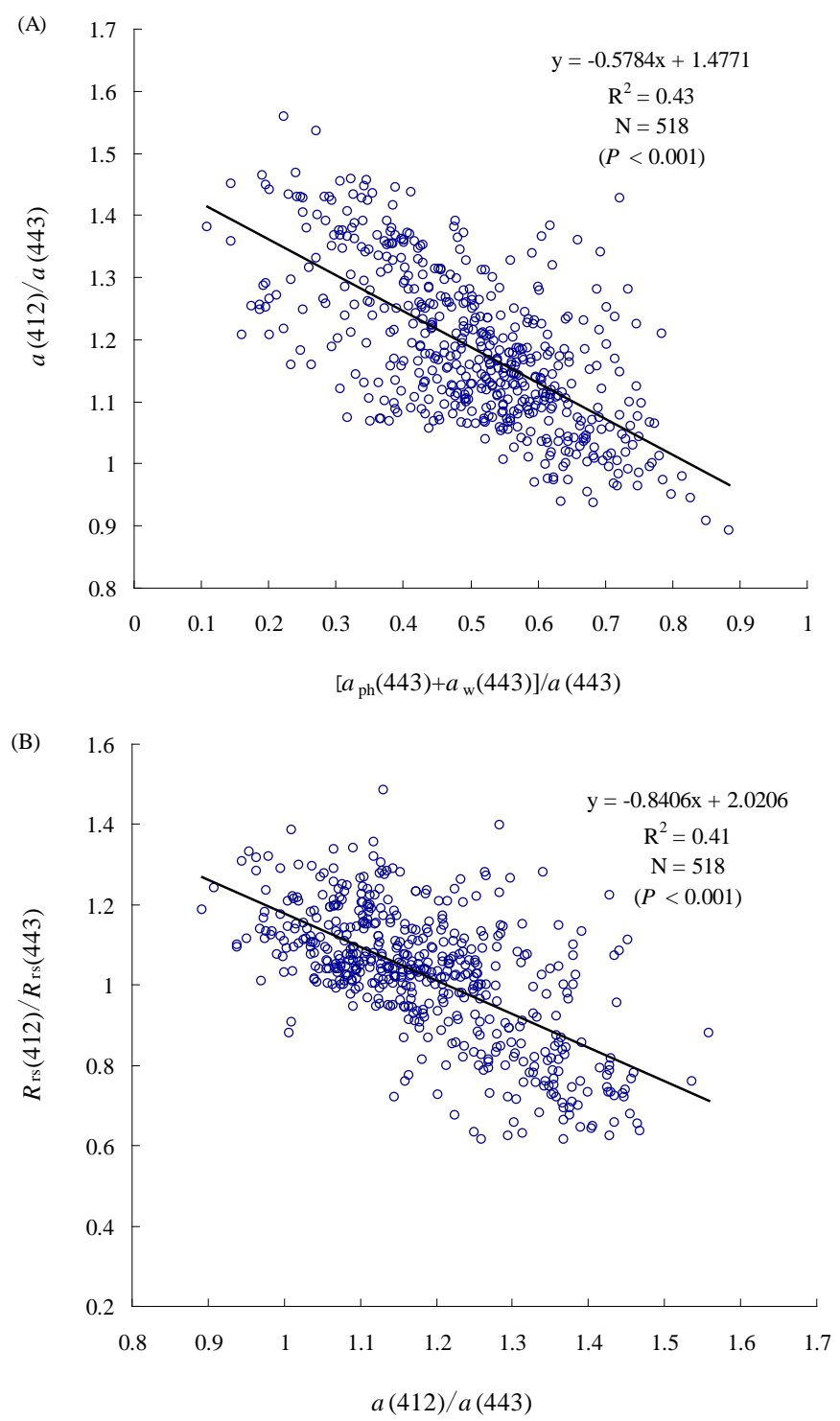

Fig. 3 

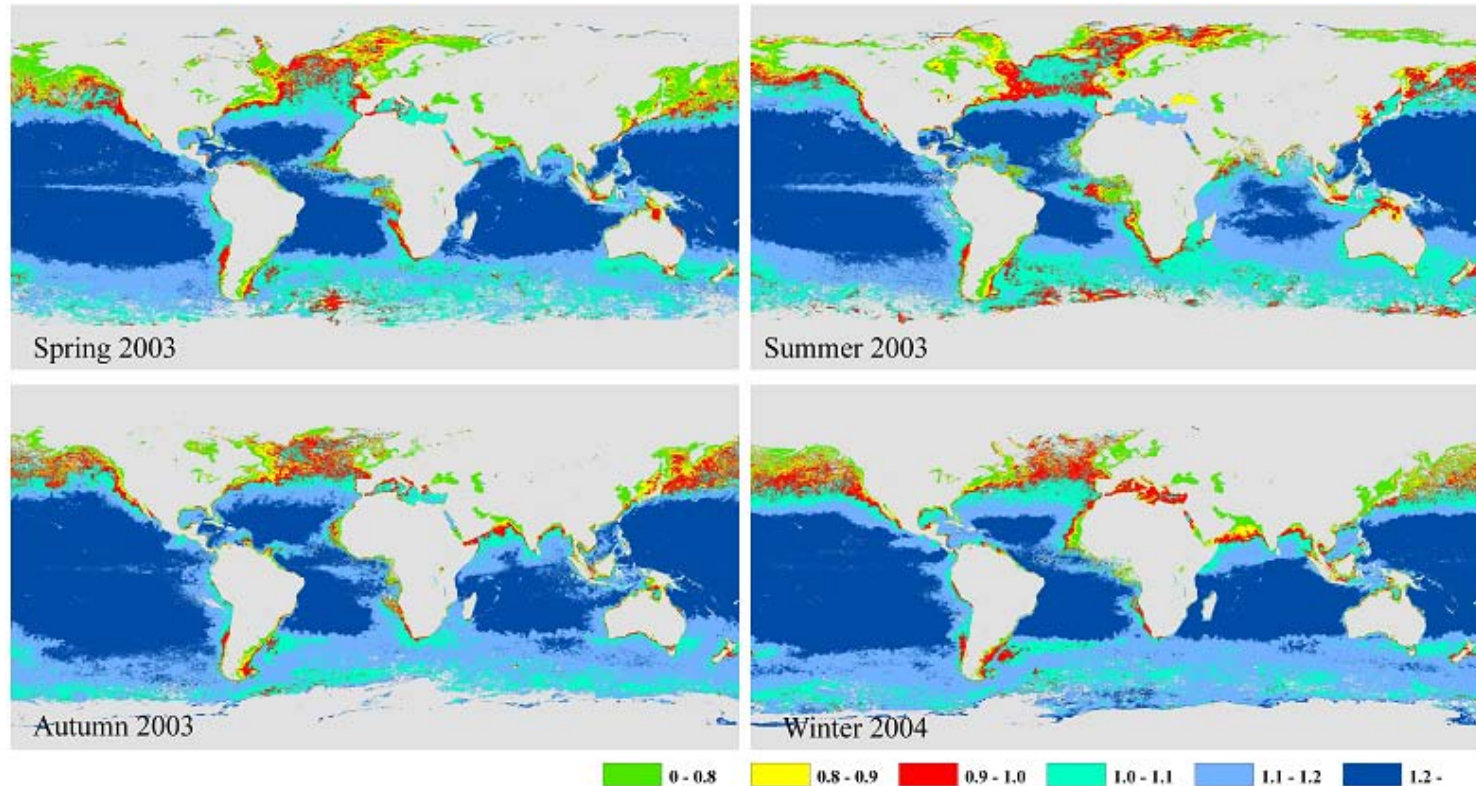

Fig. 4
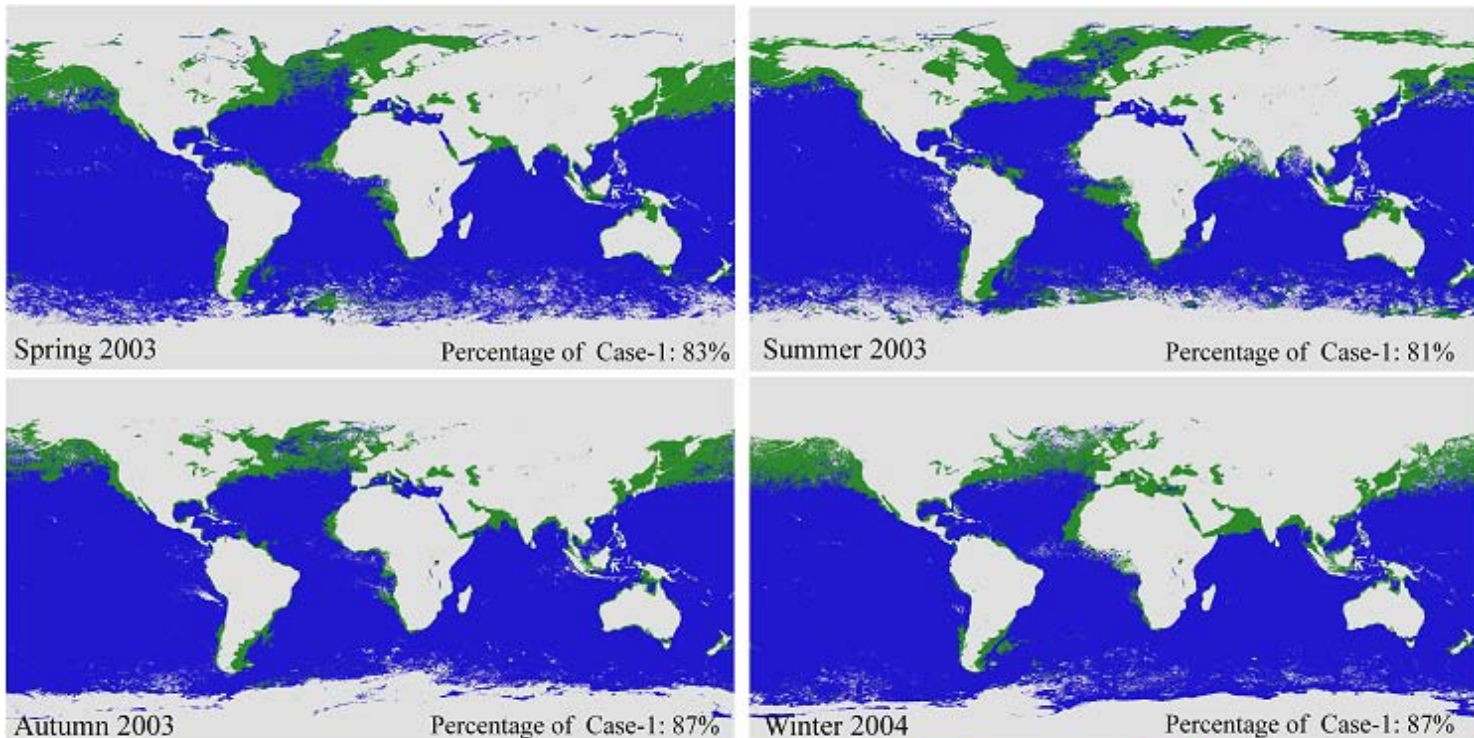

Summer 2003

Percentage of Case-1: $81 \%$

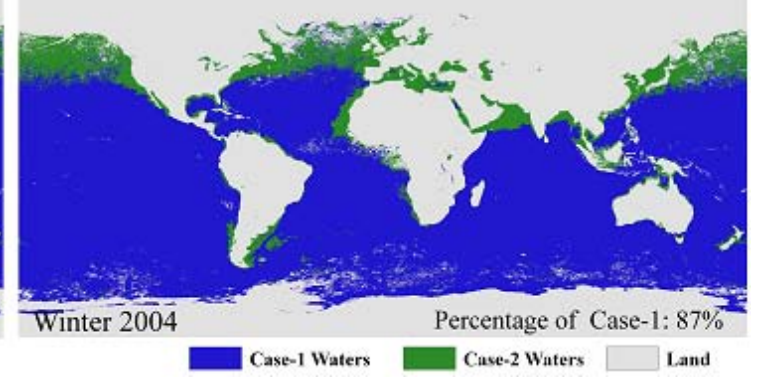

Fig. 5 


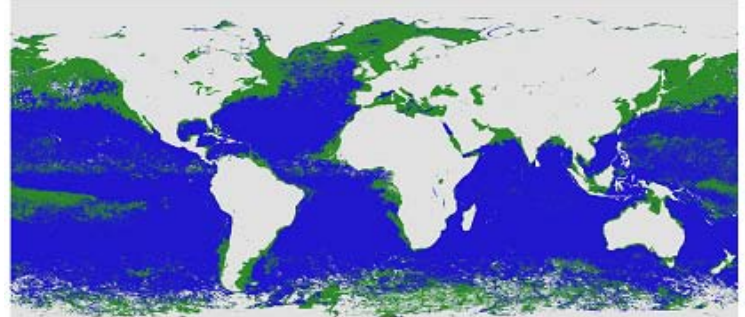

Spring 2003

Percentage of Case-1: $72 \%$

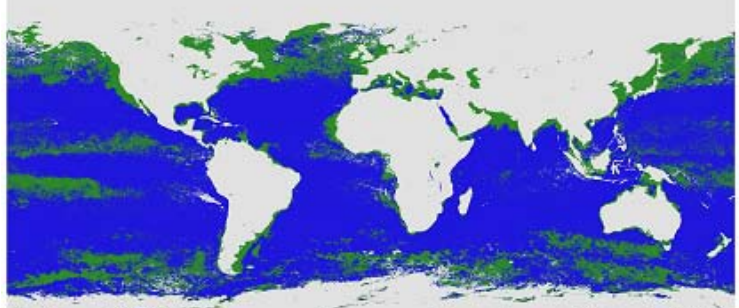

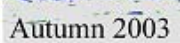

Percentage of Case-1: $74 \%$

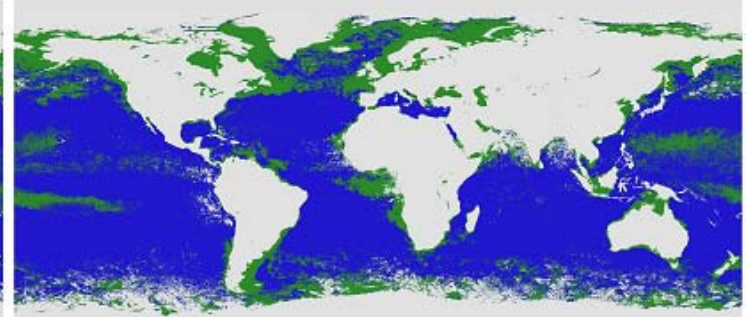

Summer 2003

Percentage of Case-1: $72 \%$

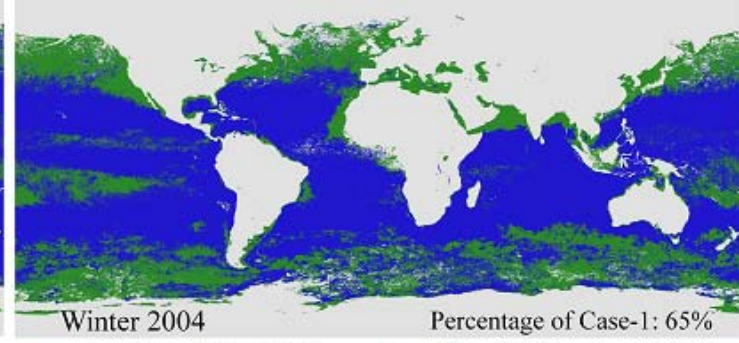

$\square$ Case-1 Waters $\square$ Case-2 Waters $\square$ Land

Fig. 6

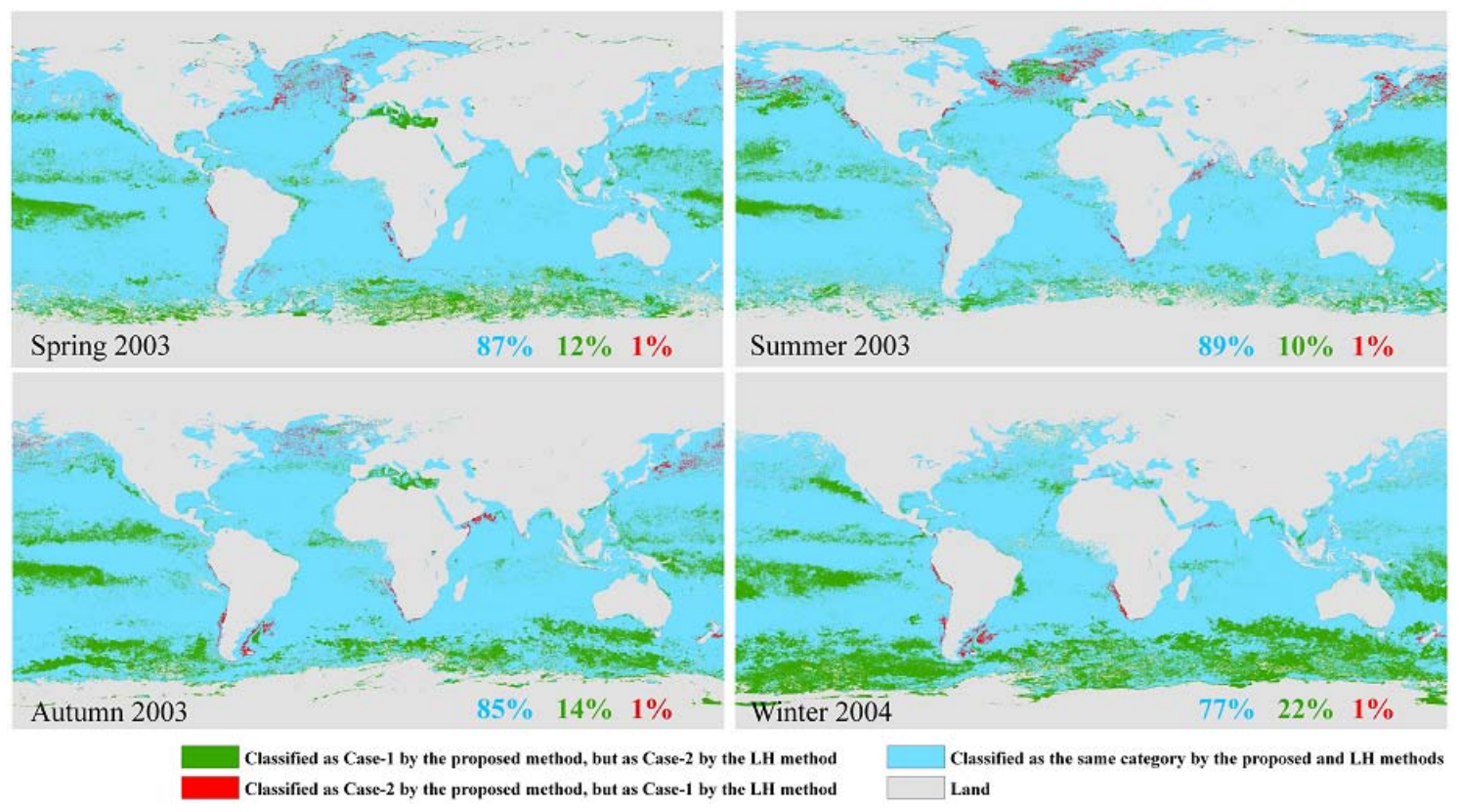

Fig. 7 


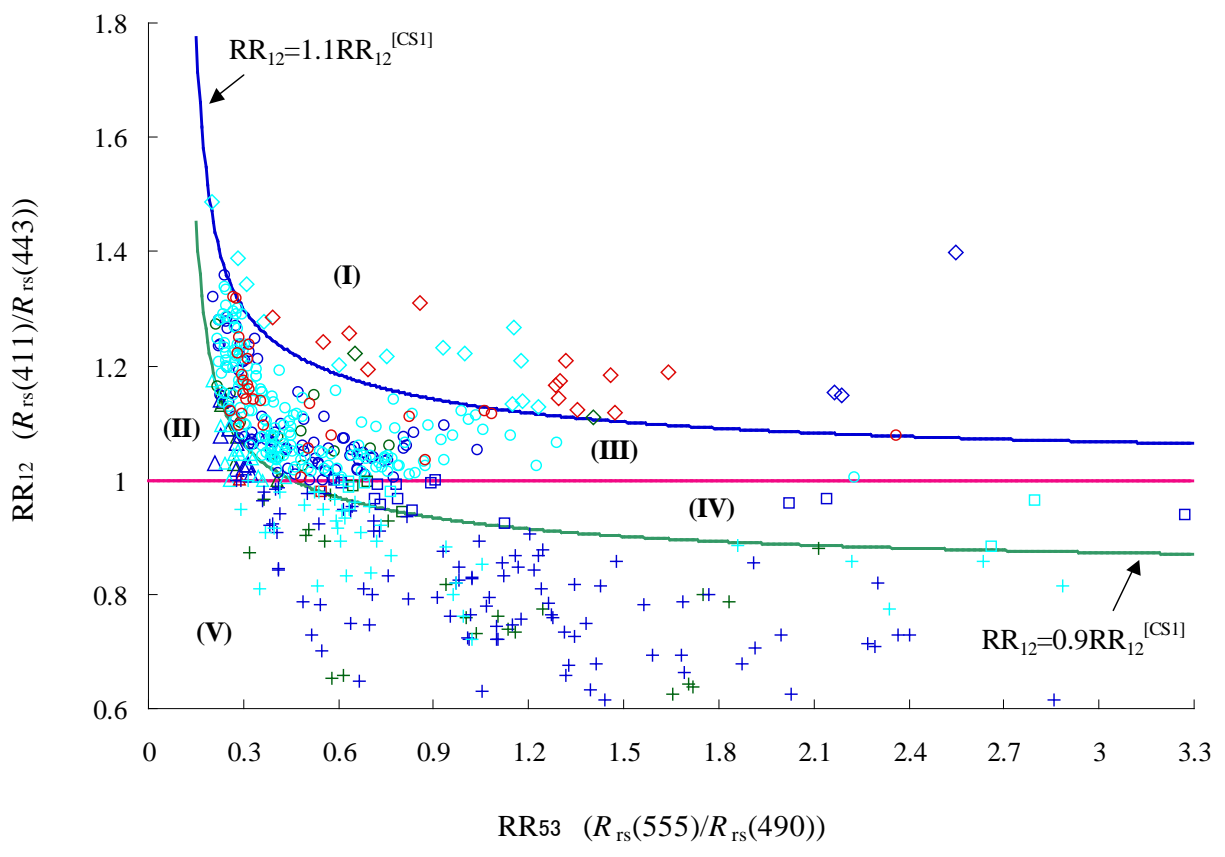

Fig. 8 

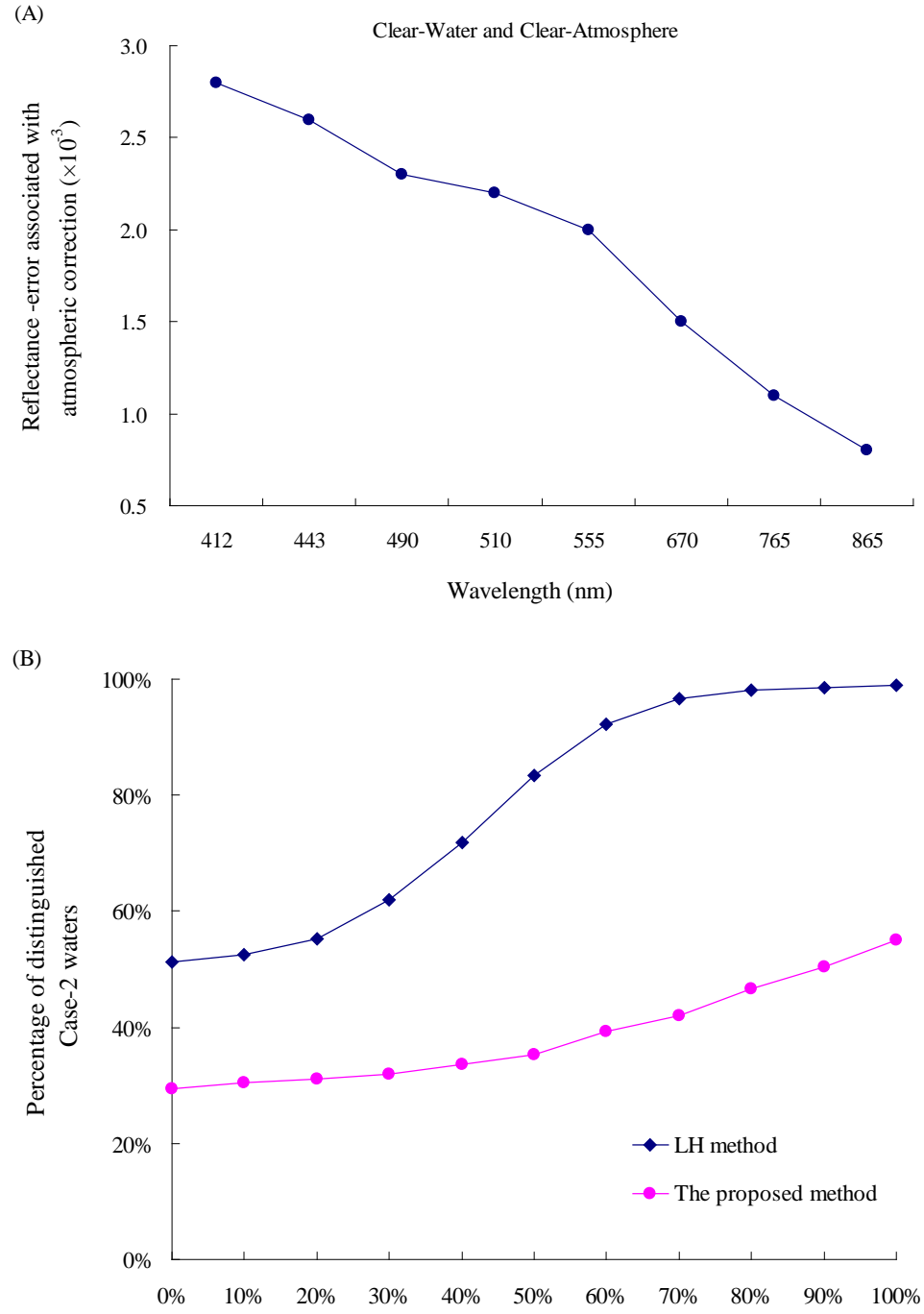

Percentage of AC errors

Fig. 9 


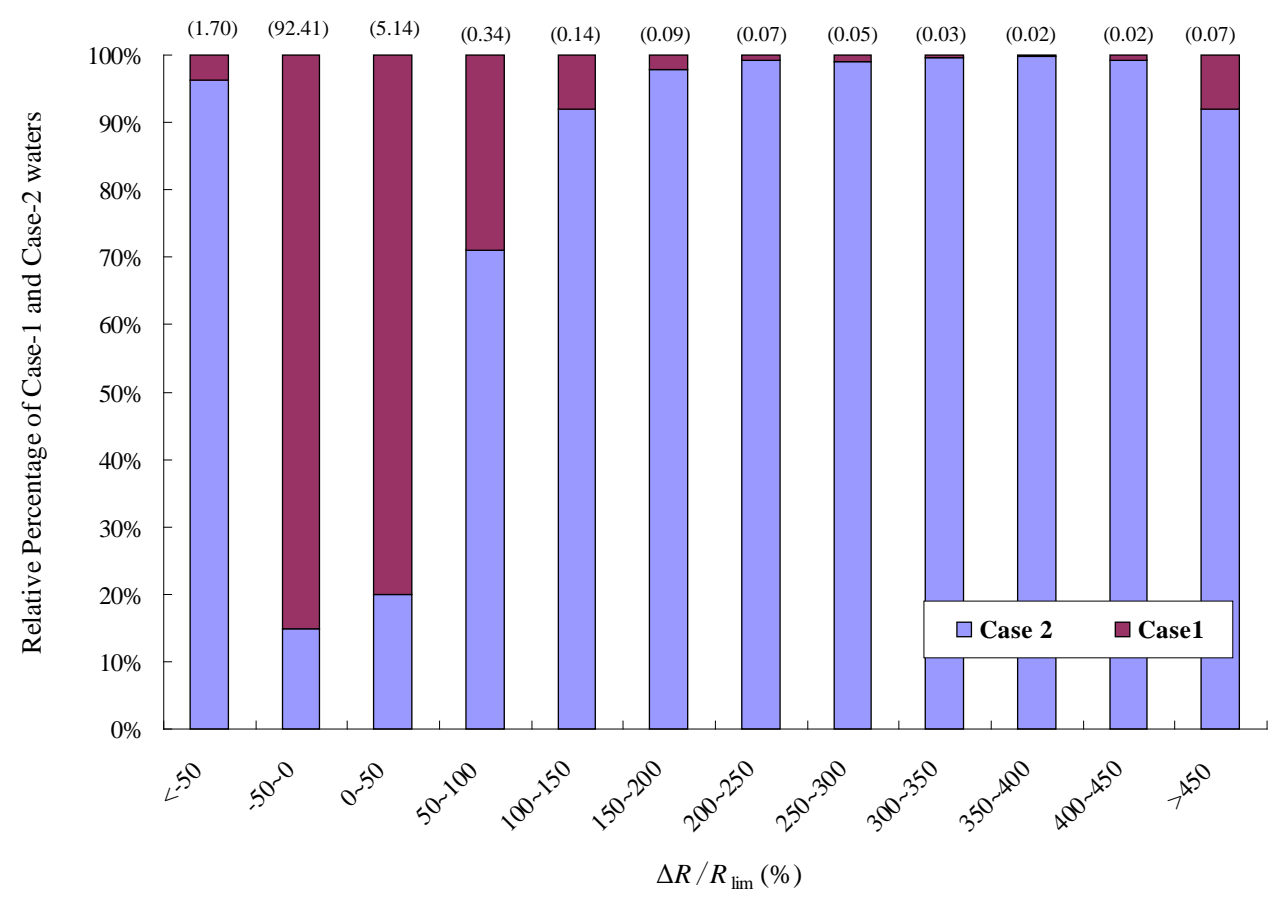

Fig. 10 


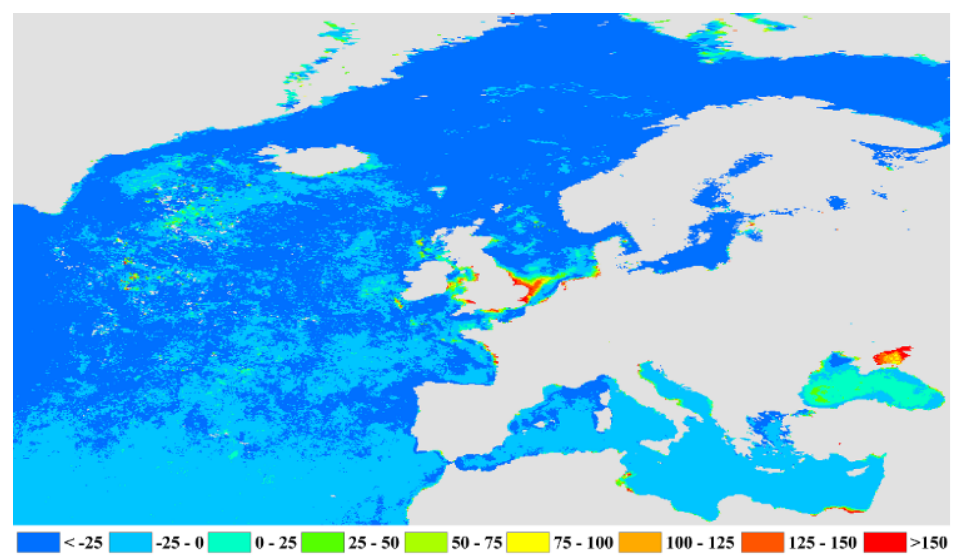

(A) $\Delta R / R_{\lim }(\%)$

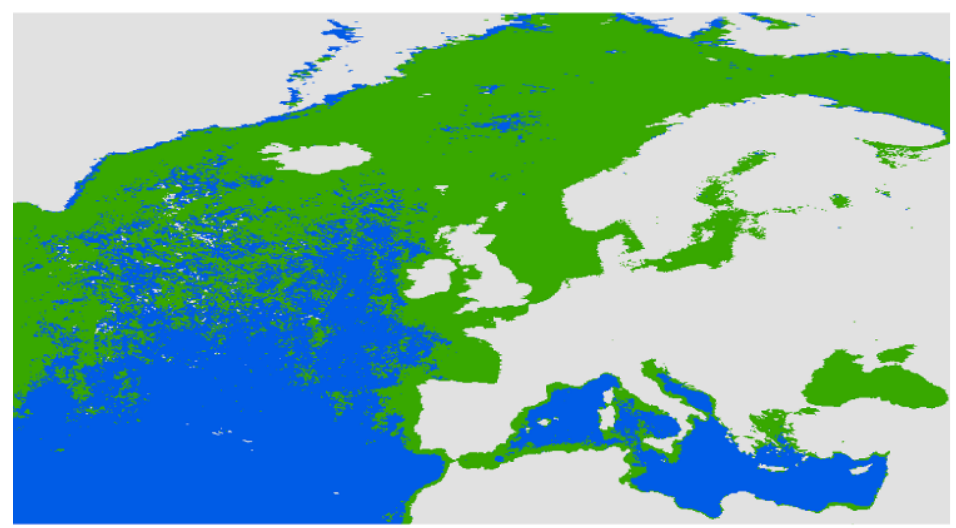

(B) Case-1 (bhe) and Case-2 (green) waters around Europe

Fig. 11 
(A)
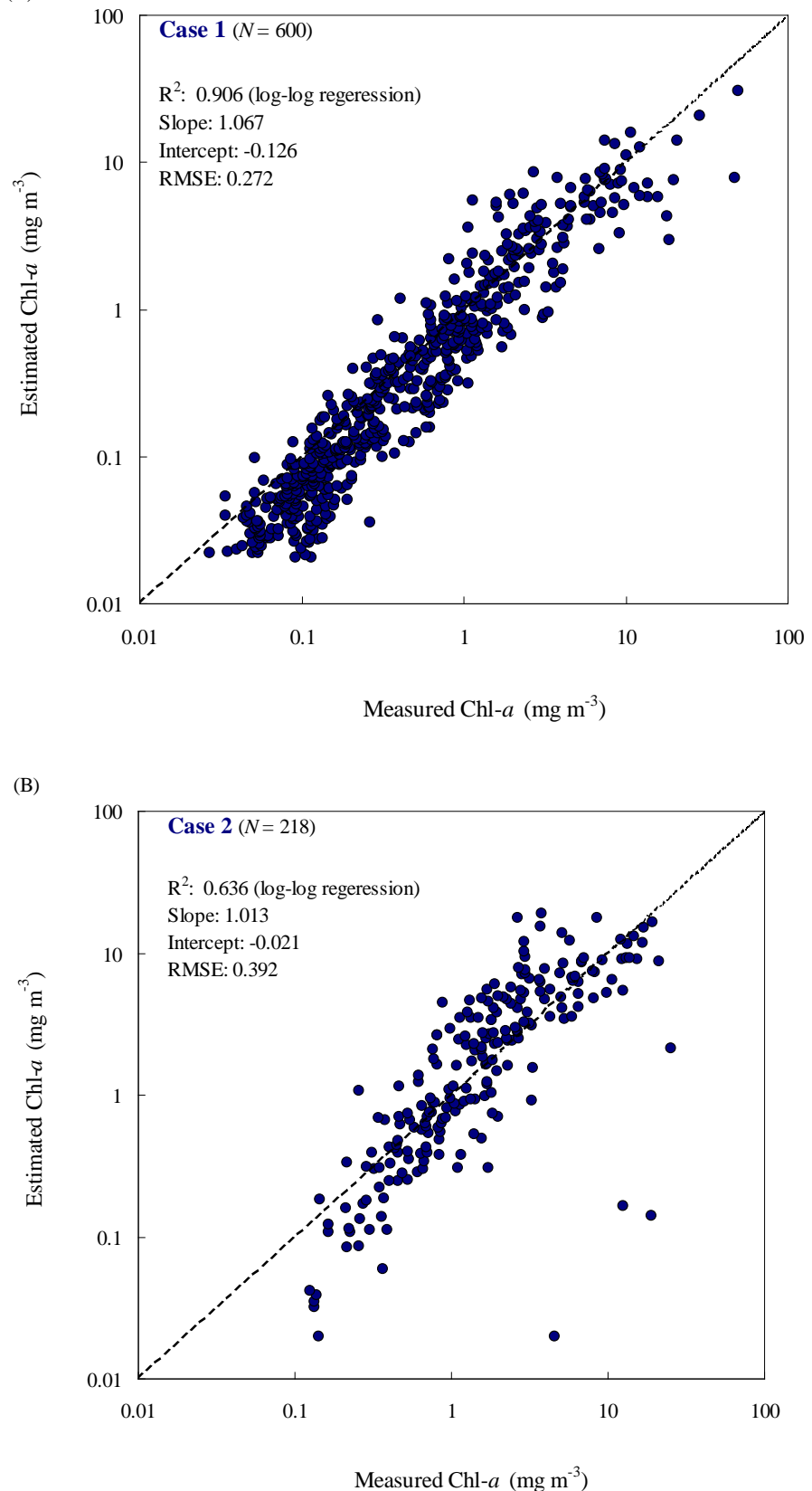

Fig. 12 